\title{
Near infrared spectroscopy: A diagnostic tool to evaluate effects of radiotherapy in the mandible?
}

\author{
Peter Reher ${ }^{\mathrm{a}}$, Bruno Ramos Chrcanovic ${ }^{\mathrm{b}, *}$, Roger Springett ${ }^{\mathrm{c}}$ and Malcolm Harris ${ }^{\mathrm{d}}$ \\ ${ }^{a}$ School of Dentistry and Oral Health, Gold Coast Campus, Griffith University, Australia \\ ${ }^{\mathrm{b}}$ School of Dentistry, Pontifícia Universidade Católica de Minas Gerais, Belo Horizonte, Brazil \\ ${ }^{\mathrm{c}}$ Dartmouth-Hitchcok Medical Center, One Medical Center Drive, Lebanon \\ ${ }^{d}$ Postgraduate Dental Education Unit, The Medical School, University of Warwick, Coventry, UK
}

\begin{abstract}
Purpose. This study tests the hypothesis that near infrared spectroscopy can be used to detect changes in haemoglobin oxygenation status in the mandible, and therefore can be used to monitor the deleterious effects of radiotherapy and the possible reversion of these effects with therapeutic ultrasound.

Methods. A probe was used to calculate the concentrations of deoxyhaemoglobin in the mandible bone of 30 volunteers with no known malignancies and 10 patients with malignancies in the head and neck region treated with radiotherapy.

Results. Although the variability of the measurements was very high, when comparing the right side to the left side of the mandible, the measurements remained relatively similar. There was a great variability between the data for each patient, there was no correlation with age.

Conclusions. The near infrared spectroscopy validation for the measurement of deoxyhaemoglobin concentrations in the mandible showed that the variability of the measurements was very high, therefore it is not appropriate to be used diagnostically for the evaluation of radiotherapy effects on the mandibular blood flow and metabolic status.
\end{abstract}

Keywords: Clinical measurement methodology, tissue oxygenation, near infrared spectroscopy, deoxyhaemoglobin concentration, radiotherapy effects, mandible

\section{Introduction}

Supply of oxygen is a vitally important function of the local tissue circulation. Along with the nutrients necessary for life, it is taken up from the cells in the capillary blood and used in the oxidative metabolic process; at the same time, the metabolites are eliminated. Adequate blood flow is required to supply oxygen to the tissue. Physiological blood flow in the tissue requires an anatomically and physiologically intact vasculature. If this is impaired as a result of a disease, a state of oxygen deficiency occurs. Depending on its extent, this oxygen deficiency can lead to cell death and tissue necrosis. The timely clinical detection and rectification of a reduced oxygen supply are of crucial importance for the scale of therapy and successful treatment [47].

\footnotetext{
*Corresponding author: Bruno Ramos Chrcanovic, Av. Raja Gabaglia, 1000/1209 Gutierrez, Belo Horizonte, MG, 30441 070, Brazil. Tel.: +55 3191625090 (mobile); +55 3132920997 (work); Fax: +55 31 25151579; E-mail: brunochrcanovic@ hotmail.com.
} 
The effect of therapeutic radiation on blood vessels has been known for many years. The changes induced are particularly well marked in arteries, veins being less severely affected [49]. The principal change seen is progressive occlusion of the vessel lumen (obliterative endarteritis) in small vessels and subsequently in larger vessels. Endothelial cell vacuolation, swelling, degeneration and shedding, transmural swelling, media muscle atrophy and fibrous hyperplasia are seen in varying degrees. Changes are progressive and start four to six weeks after radiation, ending with narrowing of the lumen and thickening of the vessel wall. An associated increase in the number of small vessels is also seen [6,20]. Previous studies on changes in postradiation femoral neck fractures suggested that vessel changes in bone might be absent or negligible $[10,41]$. Severe radiation change in the vessels may lead to progressive ischaemia of the irradiated tissues. In the case of bone, this may progress to osteoradionecrosis.

The radiotherapy effects on bone, including osteoradionecrosis can be investigated by many techniques, such as radiographs, CT scans, MRI, nuclear medicine, Doppler ultrasound, transcutaneous oxygen tension measurements, Eppendorf fine needle probe and near infrared spectroscopy. The ideal investigative tool, according to Hutchinson [33] should be able to offer the following: (1) record quantitatively and qualitatively the severity and extent; (2) monitor progress of treatment; (3) predict patients at risk; (4) predict risk factors more confidentially; (5) permit comparison of treatment regimes; (6) predict the bone level damage above which surgery is essential.

Although radiographic images are extensively used, they require a substantial alteration in mineral content and extensive involvement of the bone, which only occurs in later stages, and therefore they underestimate the extent of radiation-damaged bone, and do not correlate with the clinical status of patients $[17,18]$. Computer tomography (CT) scans have similar limitations as traditional radiographs for the mandible or maxilla, but can be helpful in temporal bone osteoradionecrosis [33]. Hermans et al. [26] examined 10 patients with osteoradionecrosis using CT scans, and observed cortical interruptions and loss of spongiosa trabeculation in all cases on the symptomatic side. Soft tissue thickening on the symptomatic side was seen in $9 / 10$ patients, and this can be difficult to differentiate from tumour recurrence. Magnetic resonance images (MRI) also have been used, and suggest that fibrosis of bone marrow occurs in osteoradionecrosis [22].

Positron emission tomography (PET) has been advocated as being able to differentiate between osteoradionecrosis and recurrent tumour [51]. Radionuclide bone scanning with technetium methylene diphosphonate $\left({ }^{99 \mathrm{~m}} \mathrm{Tc}-\mathrm{MDP}\right)$ is said to identify pathophysiologic changes in bone earlier than conventional radiography because scan changes reflect osteoblastic activity and good blood flow [2]. Technetium bone scans have also been used to monitor improvements in tissue viability, before, during and after radiotherapy. But an increased uptake of ${ }^{99 \mathrm{~m}} \mathrm{Tc}-\mathrm{MDP}$ has been seen at sites of radiotherapy (showing as 'hot' or 'black' spots on the image) during and immediately following treatment $[1,40]$. Osteoradionecrosis is also marked by an increased rate of uptake and total uptake of ${ }^{99 \mathrm{~m}} \mathrm{Tc}-\mathrm{MDP}$ relative to adjacent bone $[18,35]$. Furthermore the scans remained altered even after successful treatment. The increased uptake of this radionuclide would imply that osteoradionecrotic bone has a good blood supply, and is actively forming bone, neither of which is true. It is clear that some, as yet unexplained, mechanism accounts for this anomaly [33]. Gallium scans have also been used in osteoradionecrosis, with variable findings; consistent with the fact that osteoradionecrosis is not necessarily associated with inflammation within bone. Thus, the conditions necessary for gallium uptake may not be present and it may not be of diagnostic value for osteoradionecrosis. However, gallium scans did correlate with clinical findings following treatment, suggesting that persisting positive gallium scans may indicate the need for surgery following conservative treatment [18]. 
Colour Doppler was also used to evaluate radiation effects on the blood supply of the mouth and face. In a prospective clinical study [53], a total of 44 patients were evaluated, recording blood flow in the common carotid artery. The results show that there were no statistically significant changes between the radiated/operated side and the contralateral side, during the first 6 months after radiotherapy, probably because the measurement was made on the common carotid artery, which also has the cerebral blood flow. Usually Doppler cannot be applied to more specific vessels such as the inferior alveolar or lingual artery, because these vessels are to deep to be reached by the Doppler. Although Ethunandan et al. [19] succeed in assess the feasibility of using Doppler sonography to evaluate the characteristics of the blood flow in the mental artery, there are no studies using this measurement in radiotherapy cases so far.

Transcutaneous tissue oxygen tension $\left(\mathrm{TcPO}_{2}\right)$ studies have also been done in order to evaluate the effects of hyperbaric oxygen (HBO) therapy on neoangiogenesis $[3,44]$. The results showed that hyperbaric oxygen-induced angiogenesis becomes measurable after eight sessions, rapidly progresses to a plateau at $80-85 \%$ of nonirradiated tissue vascularity by 20 sessions, and remains at that level without further improvement with further $\mathrm{HBO}$. Transmucosal $\mathrm{TcPO}_{2}$ studies evaluating the effects of $\mathrm{HBO}$ for the treatment of osteoradionecrosis have also been done [57]. During HBO treatment, the transmucosal oxygen tension increased significantly after five dives, and after 30 dives, the increases were from a mean of 50-86\% of the measurements from normal healthy gingiva. However, it has to be remembered that $\mathrm{TcPO}_{2}$ measurements are capable of measuring the oxygen levels only at the capillary loops of the skin ad mucosa, at a depth of less then $1 \mathrm{~mm}$. Therefore, although these measurements can be used to verify the effects of hyperbaric oxygen on the skin and mucosa, it can not be used as a tool to establish such improvements in the underlying tissues. Therefore this method is unsuitable to investigate osteoradionecrosis, and the observations made by Beehner and Marx [3] and by Marx [44], regarding the effects of HBO on osteoradionecrosis should be looked at critically.

Tissue oxygen tension studies using Eppendorf fine needle probe is a new tool that allows deeper tissue $\mathrm{PO}_{2}$ measurements [46,47]. Reduced $\mathrm{PO}_{2}$ measurements could clearly be correlated with necrotically changed areas of the mandible as compared with the clinically healthy bone [50]. But it is an invasive method, and it is used as an intraoperative diagnostic tool to help in delimitate resections of bone with osteoradionecrosis.

Spectrophotometry is widely used for various types of chemical and biological analysis, and by its nature spans a broad range of wavelengths. The history of near infrared begins in 1800 with Herschel [27-29]. His experiments to find a way to filter heat from a telescope demonstrated that there was light radiation beyond what we know as the visible spectrum. This discovery was largely ignored for the better part of a century until in the mid-1950s Wilbur Kaye with Beckman Instruments published two papers that put near infrared spectroscopy on a firm footing [37,38].

In 1977, Jobsis discovered that biological tissues possessed a 'window' at near-infrared wavelengths through which light could pass with relative ease [36]. At short wavelengths light is strongly attenuated by haemoglobin and cytochromes whereas at long wavelength, water has a high absorption coefficient. However, between the wavelengths 700 and $1300 \mathrm{~nm}$, he found that a detectable amount of light was transmitted across many centimetres of animal tissues in vivo. Studying the brain of cats, he further found that only three compounds had absorption spectra in this wavelength range, which changed when the inspired oxygen concentration was altered, namely oxygenated haemoglobin $(\mathrm{HbO})$, deoxygenated haemoglobin $(\mathrm{Hb})$ and cytochrome oxidase. By measuring attenuation at a number of different wavelengths and under varying conditions of oxygenation, he was able to calculate changes in the concentrations of oxygenated and deoxygenated haemoglobin ( $\mathrm{HbO}$ and $\mathrm{Hb}$ ). Unlike haemoglobin, concentration 
changes of the total cytochrome oxidase protein occur very slowly (over days) and are therefore not easily detectable by NIRS [11].

It is thus possible to measure attenuation spectra across tissue using suitably bright light sources and suitably sensitive detectors and relate such spectra to the oxygenation level in the tissue [13]. The technique of near infrared spectroscopy relies upon two important phenomena, (1) the fact that biological tissue is relatively transparent to light in the near infrared region of the spectrum and (2) that in tissue, there are compounds whose absorption of light is oxygenation status dependent [16]. Light in the visible region of the spectrum (with wavelength between $450-700 \mathrm{~nm}$ ) is strongly attenuated in tissue and therefore fails to penetrate more than $1 \mathrm{~cm}$ of tissue. However, at near infrared (NIR) wavelengths (700$1000 \mathrm{~nm}$ ) the absorption of light is significantly lower, and with sensitive instrumentation it is possible to detect light that has been transmitted through up to $8 \mathrm{~cm}$ of tissue [12].

Haemoglobin has a distinct peak at $760 \mathrm{~nm}$ when it is completely deoxygenated $(\mathrm{Hb})$, and a broad peak around $900 \mathrm{~nm}$ when it is fully oxygenated $\left(\mathrm{HbO}_{2}\right)$. The optical properties of haemoglobin have also been applied to measure arterial oxygen tension using pulse oxymetry [55]. The early NIRS measurements were solely qualitative in nature $[4,21]$. New techniques were developed whereby quantitative measurements are obtainable such as cerebral blood flow [15], cerebral blood volume [61] and muscle oxygen consumption [8]. These techniques require a manipulation of the patient arterial oxygenation, and showed that during episodes of hypoxia, both spontaneous and induced impairment of haemoglobin oxygenation within the brain were detected together with an overall increase in the total haemoglobin concentration [43].

It is now possible to measure absolute deoxyhaemoglobin concentration from the NIR spectrum [11, 45]. The technique uses second-differential spectroscopy to determine the relative concentration of deoxyhaemoglobin $(\mathrm{Hb})$ to tissue water by fitting of the distinct spectral features of these two cromophores in the 710-840 $\mathrm{nm}$ region of the near infrared spectrum [45]. Since the concentration of tissue water is generally known with accuracy of a few per cent, one can then obtain the absolute concentration of deoxyhaemoglobin $([\mathrm{Hb}])$. However, it is not possible to measure the absolute concentrations of the oxygenated haemoglobin $(\mathrm{HbO})$ because it has no distinct features in the second differential of the attenuation spectrum.

Clinical applications of this technique over the past decade have principally been focused on the cerebral circulation. Near infrared spectroscopy has been used to evaluate neonatal cerebral hypoxia and blood flow [15,60], to monitor raised intracranial pressure [7], to evaluate the effects of gravitational forces on the cerebral oxygenation in fighter pilots [24], to evaluate oxygenation changes in the human forearm muscle [25], and to evaluate peripheral vascular disease [8]. It has also been used to measure response of normal tissue oxygenation after acute trauma [54], invasive catheter detection of lipid core coronary plaques [23,59], and even in helping caries detection [9]. Commonly, a pulse oximeter with a fingertip transmission sensor is used for the monitoring of oxygen saturation.

Near infrared spectroscopy was first used to evaluate osteoradionecrosis by Hutchinson et al. [34]. Since osteoradionecrosis is considered to be a chronic non-healing wound due to hypoxia and hypovascularity, NIRS seems to be a useful technique to measure possible decrease in oxygen saturation. In the osteoradionecrosis sites, a decreased peak of deoxygenated haemoglobin was observed. Telfah [56] evaluated 32 patients who had been given radiotherapy, using NIRS, 16 of them with ORN. His study showed marked decrease in levels of deoxyhaemoglobin concentrations in the ORN tissue. These observations could also be correlated to clinical findings. This study suggested that there was no spontaneous improvement in blood supply with time, but a significant improvement following a course of therapeutic ultrasound. However, none of these two mentioned studies performed a full evaluation of the NIRS 
technique for the mandible in relation to reproducibility between measurements and in the same patient over time. These are crucial, since our preliminary observations showed a great variability in the results.

This study tests the hypothesis that near infrared spectroscopy (NIRS) can be used to detect changes in haemoglobin oxygenation status in the mandible, and therefore can be used to monitor the deleterious effects of radiotherapy and the possible reversion of these effects with therapeutic ultrasound. The aims of this study are:

(1) To design an appropriate probe to make NIRS measurements clinically in the human mandible.

(2) To validate the measurements obtained in relation to reproducibility in the same subject over a period of time.

(3) To validate the measurements obtained in a control group of different ages to identify possible normal age changes in the haemoglobin oxygenation status.

(4) To identify if the possible deleterious effects of radiotherapy can be measured with NIRS.

\section{Materials and methods}

\subsection{The NIRS system}

The system used for measurements of tissue oxygenation in this study is shown schematically in Fig. 1. The light source is a 100 Watt quartz halogen lamp (current stabilised) with a fibre optic output (Oriel 77501, Stratford, CT, USA). Various colour glass filters with long pass characteristics at visible wavelengths are employed to eliminate higher spectra. A $2 \mathrm{~mm}$ diameter ( $3 \mathrm{~mm}$ with the new probe) Superflex glass fibre optic bundle (Eurotec Fibre Optics, Doncaster) carries light to the sample.

Light transmitted through the tissue sample is collected by a second Superflex fibre optic bundle, with a cross section changing from a circle of $3 \mathrm{~mm}$ diameter at the sample to a $5 \mathrm{~mm}$ high by $1.4 \mathrm{~mm}$ slit a the input to the spectrograph. The spectrograph itself has a $27 \mathrm{~cm}$ focal length with an input aperture of f/4. Light enters through a variable width slit of micron resolution and is dispersed by a custom made ruled grating of 600 lines/mm blazed at $750 \mathrm{~nm}$ (Spex 270M, Instruments SA, France).

An array detector at the focal point of the output mirror performs detection of the dispersed light. The detector consists of an electrically cooled charged coupled device (CCD) camera (Wright Instruments, UK). This camera uses a 1024 by 256 array of $26 \mu \mathrm{m}$ square elements (EEV CCD30-11, UK). The 1024

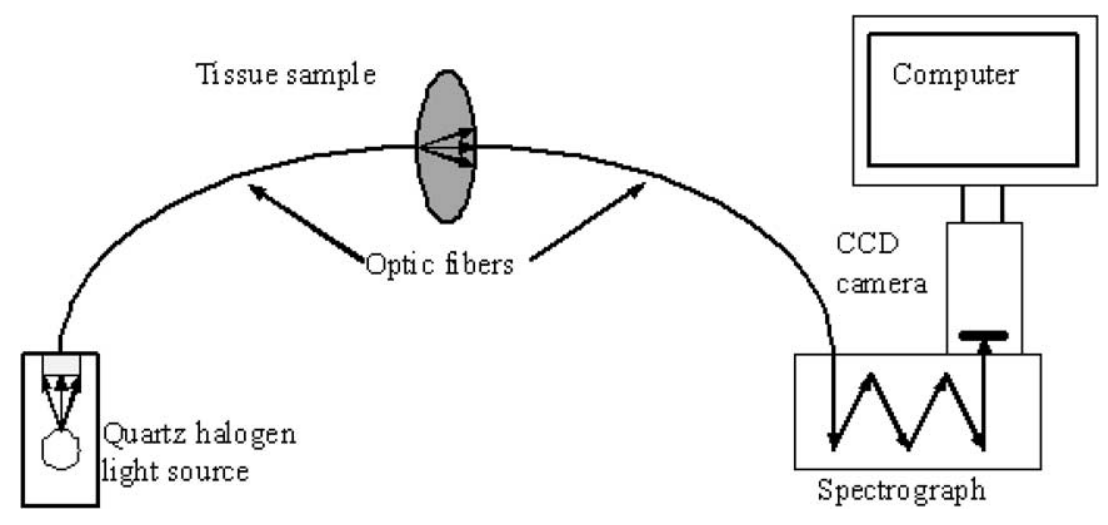

Fig. 1. Diagrammatic representation of the NIRS system used. 
elements are set across the wavelength dispersed axis while the 256 vertical elements record an image of the input slit. It has a pixel bandpass of $0.15 \mathrm{~nm}$, a spectral resolution of $0.3 \mathrm{~nm}$ and a total wavelength range of $154 \mathrm{~nm}$. Light incident on the CCD causes charge to accumulate in the elements, and this charge is then read out and digitised by a 16 bit analogue to digital converter (ADC). Each count of the ADC can be set equivalent to $1-4$ electrons.

\subsection{Probe design}

The probes used in the previous studies for NIRS measurements in the mandible consisted of two optic fibre bundles held by hand [34]. This set-up was used initially in the experiments reported here, however the variability was very high, because the light had to pass through several tissue types, from skin to mucosa, and therefore measurements of bone itself were not reliable. Furthermore, it was almost impossible to keep the two optic bundles in the same spatial orientation between each other, making repeated measurements very difficult. A second person was also always needed to operate the computer.

Therefore it was decided to design a new probe were both light source and receptor could be introduced in the mouth, allowing measurements of the mandible alone (and overlying soft tissue). The contribution from skin and cheek was therefore avoided, and with the probes held with one hand, the other could operate the computer, avoiding a second operator. The two optic fibre bundles are connected to the probes, so that the emitting light bundle shines directly into the receiving, or caption bundle, avoiding therefore possible orientation changes. Figure 2 shows schematically how the probes were designed and constructed.

\subsection{Calibration}

When the system is switched on, the CCD camera immediately starts to cool down. While the CCD is cooling (to approximately $195^{\circ} \mathrm{K}$ ) the CCD is continually "charged cleared" to prevent trapped charge
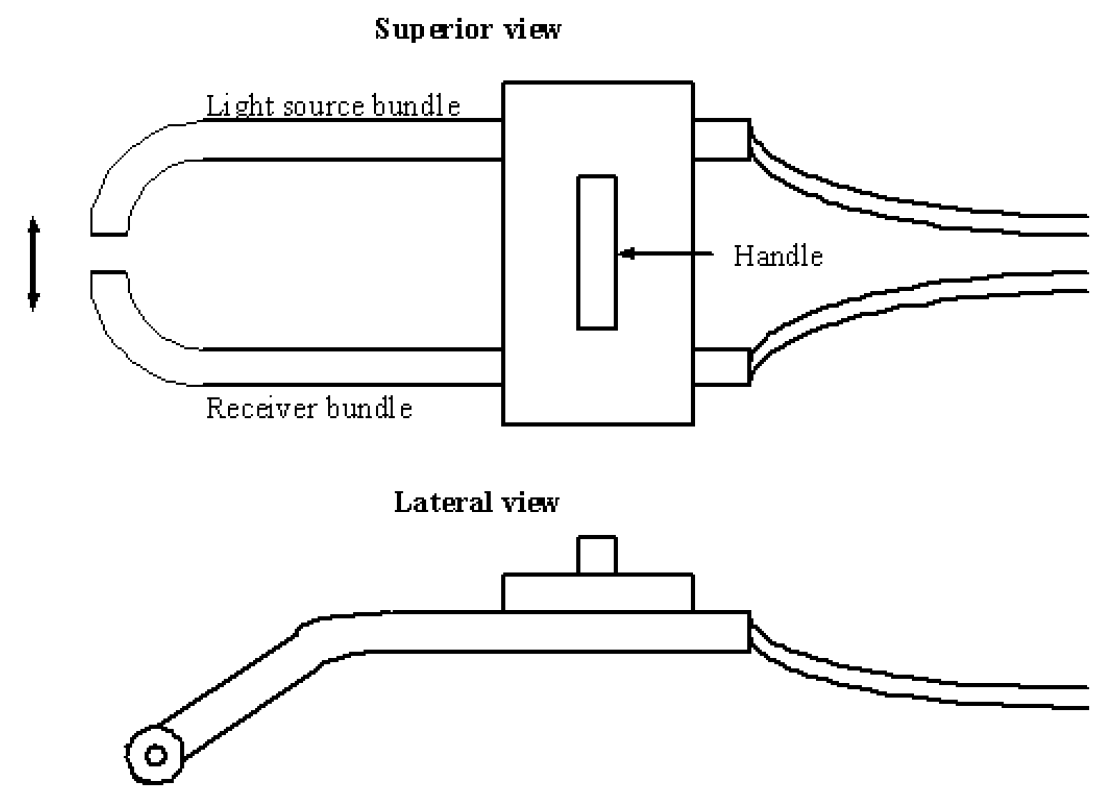

Fig. 2. Schematic representation of the new probe design used for NIRS measurements in the mandible. 
and hence reduce the dark signal during the measurement. The system is then wavelength calibrated with a low pressure neon lamp to an accuracy of better than $0.1 \mathrm{~nm}$. The calibration and further data manipulation is performed with a software written by Dr. Roger Springett (at the study time, working at the Department of Medical Physics and Bioengineering, UCL).

Finally, an air reference for that day needs to be taken. Another scan is taken using the light source and the probes set apart, until a good reading is obtained (1-2 $\times 10^{5}$ electrons). Three scans are then taken, each with 9 measurements of $0.1 \mathrm{~s}$. An average of these three scans is calculated and used as the air reference of the day. To scan the patients, the system was set up to take 5 scans of $0.1 \mathrm{~s}$, and readings between 0.8 and $2.0 \times 10^{5}$ electrons for each scan were accepted.

\subsection{Patients scanning}

In the previous NIRS studies in the mandible [34,56], the light source was shone through the face from skin to the oral mucosa. In this way, it was difficult to evaluate the contribution of all the different tissues (skin, subcutaneous tissue, muscle, parotid gland, bone, submucosa and mucosa), leading to problems in terms of calculation of the absolute concentrations of deoxyhaemoglobin in the bone. Therefore, it was decided to place the probes as close as possible to the bone, our primary target. In this way, one arm of the probe was placed in the buccal vestibule and the other arm in the lingual side of the mandible. The probes were placed as far down as possible, trying to shine the light through bone instead of only interpapillar gingiva. The probe was always placed between teeth to avoid the interference from the dental roots. The light emitting and the light receiving probes were compressed against the mucosa as much as possible. To avoid pain, the probe ends were protected with a small tube of silicon. Before each scan, the probes were covered with a sterile clear cover.

The mandible of each patient/volunteer was scanned at 6 different points, three on each side of the mandible. The points were: (1) canine - between the lateral incisor and the canine; (2) premolar between the two premolars; and (3) molar - between the first and second molar. When an area was partially edentulous, the scans were taken in similar areas.

Because of the great variability noted in the preliminary measurements performed, it was decided to measure each point in the mandible 5 times. As mentioned, each measurement consisted of 5 scans of $0.1 \mathrm{~s}$. Thus, a total of 25 scans for each selected mandibular point was performed for each patient/volunteer. This was a big improvement form the previous measurements, which consisted of only 1 measurement with 3 scans.

\subsection{Calculating the results using the software}

After the scans have been taken, the results were analysed to calculate the absolute concentrations of deoxyhaemoglobin with the same software program (Dr. Roger Springett, Department of Medical Physics and Bioengineering, UCL). The intensity data from each measurement has a pattern similar to that shown in Fig. 3A. This represents the sum of the $5 \times 0.1 \mathrm{~s}$ scans for only 1 measurement of the mandible.

The spectrum is normalised using the air reference data file obtained previously and converted in units of light attenuation. The result of this is an attenuation spectrum for the tissue, the units of attenuation being optical densities (ODs) (Fig. 3B).

The second differential of this attenuation is then calculated, and the resulting graph is shown in Fig. 3C. The second differential compound spectra of water and deoxyhaemoglobin are formed. Finally, 


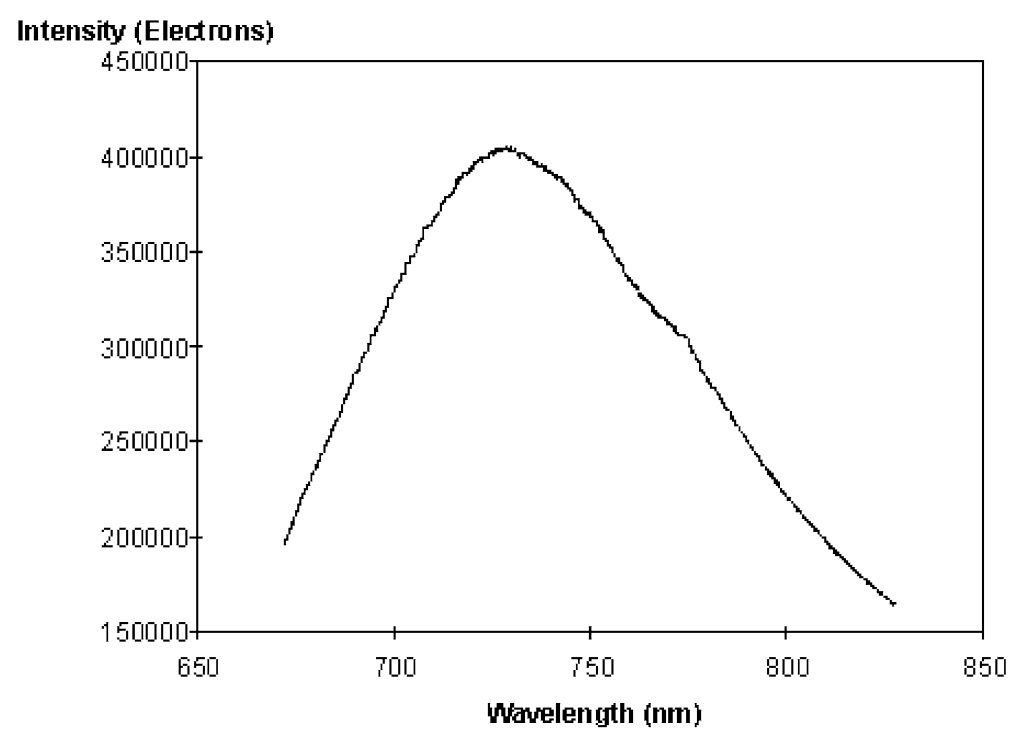

(A)

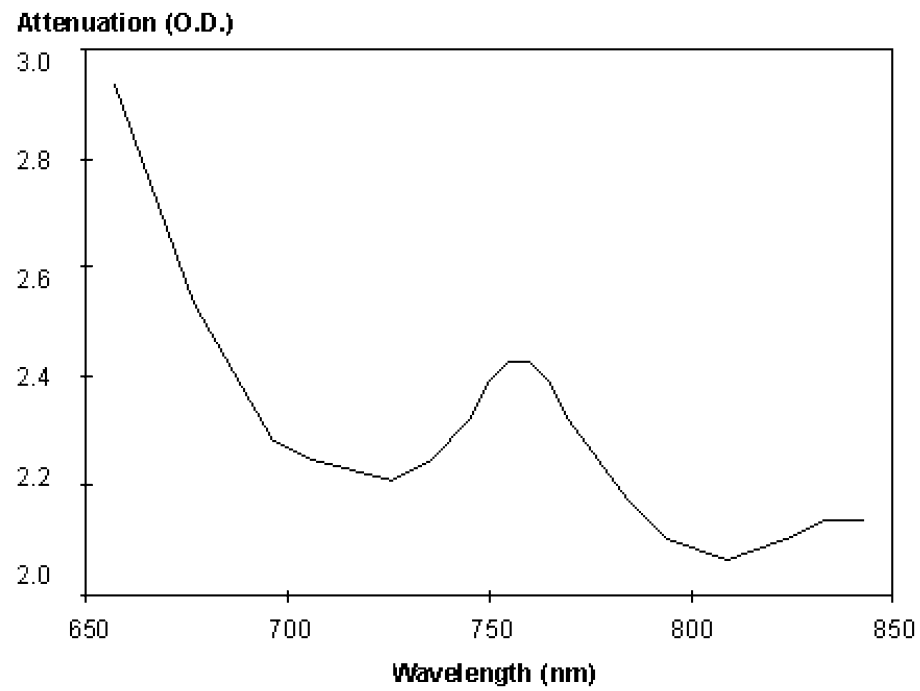

(B)

Fig. 3. Calculating the value for the deoxyhaemoglobin. (A) A typical NIRS transmission spectrum across the mandible. Light intensity is measured in units of electrons and wavelength in units of nanometres (nm). (B) Attenuation of the transmission across the mandible. (C) Second differential of the attenuation spectrum across the mandible. (D) Least-squares fit the second differential spectrum obtained over the wavelength $710-840 \mathrm{~nm}$ with the reference compound spectra of $\mathrm{Hb}, \mathrm{HbO}$ and $\mathrm{H}_{2} \mathrm{O}$ at $37^{\circ} \mathrm{C}$ (model). The sharp lines at both extremes are artefacts of the numerical method.

least squares fit the second differential spectrum obtained over the wavelength 680-800 nm with a reference compound spectra of $\mathrm{Hb}, \mathrm{HbO}$, coconut oil and $\mathrm{H}_{2} \mathrm{O}$ at $37^{\circ} \mathrm{C}$ (Fig. 3D). The spectra of coconut oil were used to mimic the fat presence in the mandible, since it has similar spectra as normal fat.

The values obtained from this least squares fitting procedure were saved as ASCII file, and transferred to an Excel $^{\circledR}$ worksheet. The estimation of the absolute concentration of deoxyhaemoglobin ( $\mathrm{Hb}$ ) (in 


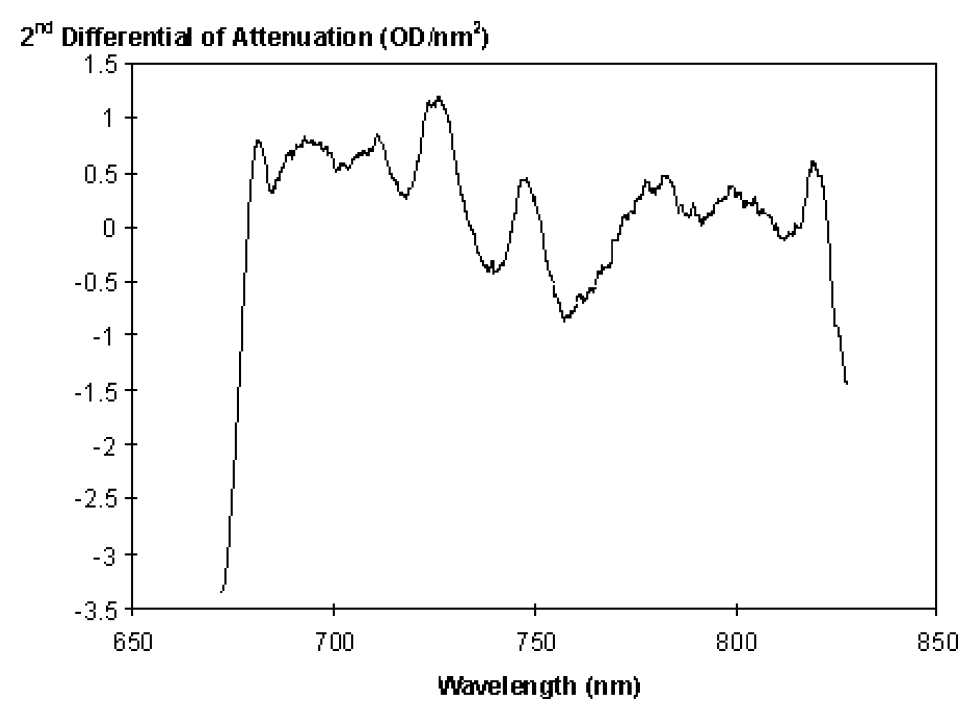

(C)

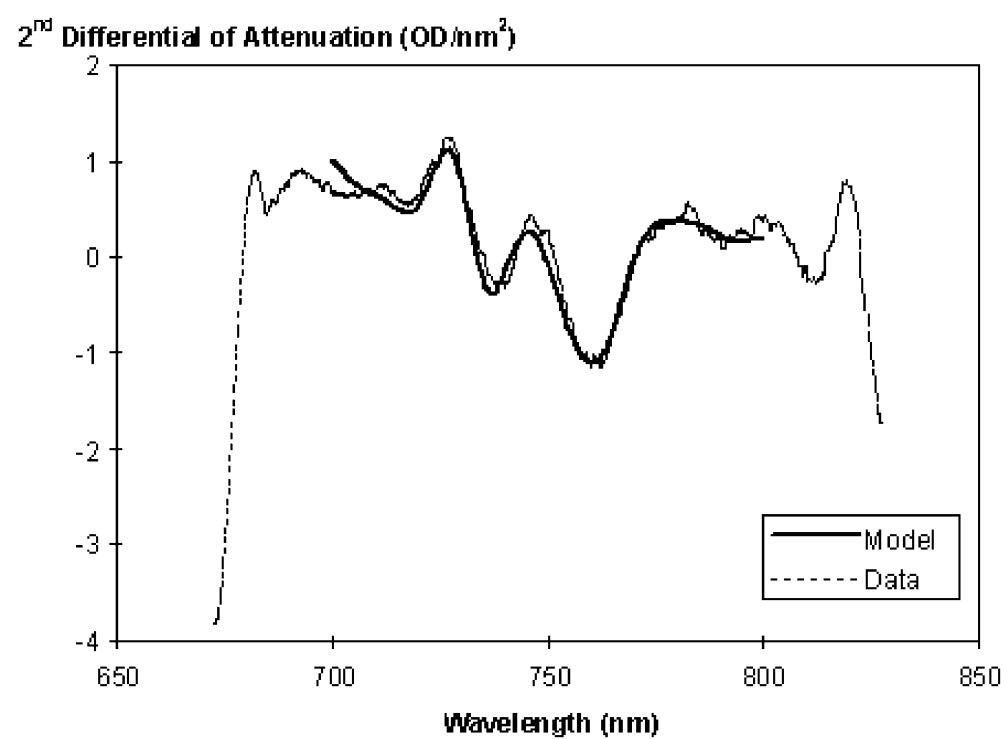

(D)

Fig. 3. (Continued.)

millimolar) is given by the formula:

$$
\text { Abs }[\mathrm{Hb}]=\frac{\mathrm{Hb}}{\text { Water }} \times 0.4 \text { (estimated water concentration). }
$$

\subsection{Volunteers}

Thirty volunteers were included in this study, with age range of 24-84. Eighteen (18/30;60\%) males with age range of 24-84, median 32 years and twelve $(12 / 30 ; 40 \%)$ females with age range $27-84$, median 45 years. 
All patients had no known malignancies or relevant diseases. The scans were performed in the same time of the day (10-12 am). NIRS spectra were generated from six points in the mandible and repeated 5 times, as mentioned (canine, premolar and molar, in both sides of the mandible).

The following analyses were performed:

(1) Intra-subject variability. One of the volunteers was examined with NIRS at 6 different dates over a period of 3 months. The results were analysed with single factor ANOVA to detect significant variability between the readings of each day. Furthermore analysis comparing measurements of one side to another were also performed.

(2) Inter-subject variability. This analysis looked at the variability of the deoxyhaemoglobin concentration measurements in relation to age. Correlations were made at each scanned point to see if there was any association between age and deoxyhaemoglobin concentration in the mandible. Furthermore the data of the 30 volunteers was analysed looking for variability between subjects readings.

\subsection{Patients}

Ten patients that had malignancies treated with radiotherapy were also included in the study, to be compared to the volunteer group, and see if NIRS is able to measure any change in the deoxyhaemoglobin concentration in the mandible caused by radiotherapy. The age range of the patients was 36-70. Four males (40\%) with age range 36-70, median 57 years and six females (60\%), with age range 41-65, median 53.

All patients had malignancies in the head and neck region, and all were treated with external beam radiation (teletherapy - 40-60 Gy) applied in fractions of 1-1/2 to 2 Gy per session, 5 days a week. To be included in this study, the mandible had to be involved in the radiation field.

The data obtained from these patients was compared to that of a group of gender and age matched volunteers, in order to see if there was any difference in the measurements.

The work has been approved by the Ethical Committee of the Eastman Dental Institute, University College London.

\section{Results}

\subsection{Intra-subject variability}

Table 1 shows the results obtained from the NIRS measurements (deoxyhaemoglobin concentrations) in the same subject, over a period of three months. The table shows the average value obtained for the measurements taken in the 6 different days. To analyse the data, all the 30 values obtained for each mandibular point were used, and grouped per day. The analysis of variance was used to determine if there was any difference between the 5 measurements taken for each day, compared to the other days.

As can be noted, there was a highly significant difference between the measurements taken each day. To exemplify the great variability noted, NIRS measurements on the right canine point varied between 0.159 and 0.820 milimolar of absolute deoxHb. The lowest and the highest mean of a day were 0.277 and 0.673 , respectively (Table 1 ).

Although the variability of the measurements was very high, when comparing the right side to the left side of the mandible, the measurements remained relatively similar. Table 2 shows the results of 
Table 1

Variability of NIRS measurements (deoxyhaemoglobin concentrations in milimolar) over a period of three months, in the same subject. The values shown represent the mean value of the 5 measurements taken in each day

\begin{tabular}{|c|c|c|c|c|c|c|}
\hline & \multicolumn{3}{|c|}{ Right } & \multicolumn{3}{|c|}{ Left } \\
\hline & Molar & Prem. & Canine & Canine & Prem. & Molar \\
\hline$\overline{\text { Day } 1}$ & 0.274 & 0.162 & 0.328 & 0.333 & 0.203 & 0.263 \\
\hline Day 2 & 0.241 & 0.140 & 0.453 & 0.497 & 0.197 & 0.348 \\
\hline Day 3 & 0.475 & 0.430 & 0.620 & 0.462 & 0.342 & 0.537 \\
\hline Day 4 & 0.302 & 0.121 & 0.277 & 0.419 & 0.145 & 0.282 \\
\hline Day 5 & 0.395 & 0.369 & 0.673 & 0.553 & 0.419 & 0.400 \\
\hline Day 6 & 0.456 & 0.312 & 0.438 & 0.608 & 0.345 & 0.471 \\
\hline Mean & 0.347 & 0.259 & 0.449 & 0.479 & 0.275 & 0.383 \\
\hline St. Dev. & 0.096 & 0.115 & 0.162 & 0.136 & 0.108 & 0.104 \\
\hline CI Interval & 0.032 & 0.039 & 0.054 & 0.049 & 0.038 & 0.037 \\
\hline Min & 0.208 & 0.091 & 0.159 & 0.169 & 0.116 & 0.225 \\
\hline Max & 0.538 & 0.469 & 0.820 & 0.744 & 0.476 & 0.587 \\
\hline ANOVA* & $4.75 \mathrm{E}-10$ & $4.45 \mathrm{E}-07$ & $7.13 \mathrm{E}-13$ & 0.010557 & $7.8 \mathrm{E}-10$ & $1.74 \mathrm{E}-12$ \\
\hline
\end{tabular}

Note: ${ }^{*}$ The ANOVA was used comparing the 5 measurements taken for each day to the other days. The results show the $p$-values, note that these were highly significant $(p<0.001)$ for all mandibular points.

Table 2

Comparison between right and left side measurements in the same subject in 6 different days (values show $p$-values after $t$-test analysis)

\begin{tabular}{lccc}
\hline & Canine & Premolar & Molar \\
\hline Day 1 & $p=0.6539$ & $p=\mathbf{0 . 0 4 2 4}$ & $p=0.483$ \\
Day 2 & $p=0.5754$ & $p=0.1039$ & $p=\mathbf{0 . 0 0 0 1}$ \\
Day 3 & $p=\mathbf{0 . 0 0 3 5}$ & $p=\mathbf{0 . 0 0 7 2}$ & $p=\mathbf{0 . 0 4 9 5}$ \\
Day 4 & $p=0.1052$ & $p=0.3704$ & $p=0.3443$ \\
Day 5 & $p=\mathbf{0 . 0 3 7 2}$ & $p=\mathbf{0 . 0 4 7 1}$ & $p=0.8592$ \\
Day 6 & $p=\mathbf{0 . 0 0 3 7}$ & $p=0.3094$ & $p=0.5345$ \\
Average all days & $p=0.9232$ & $p=0.9437$ & $p=0.6715$ \\
\hline
\end{tabular}

the unpaired two-tailed $t$-test, comparing each point of the mandible with the other side. As can be noticed, the differences were mostly not significant, however on 8 occasions there was a difference (marked in bold). By averaging the observations for each day, there was no significant difference in the measurements, comparing left to right (Table 2 and Fig. 4).

\subsection{Inter-subject variability}

Because of the great variability observed in the intra-subject evaluation, all the following measurements with the volunteers were repeated 5 times for each point, and the averaged values are shown in the following tables. Again, a great variability in the data was observed, as shown in Tables 3 (20-30 years age group), 4 (31-50 group) and 5 (51-84 group). There was a great variability between the data for each patient, even keeping in mind that the values shown were already an average of 5 measurements. 


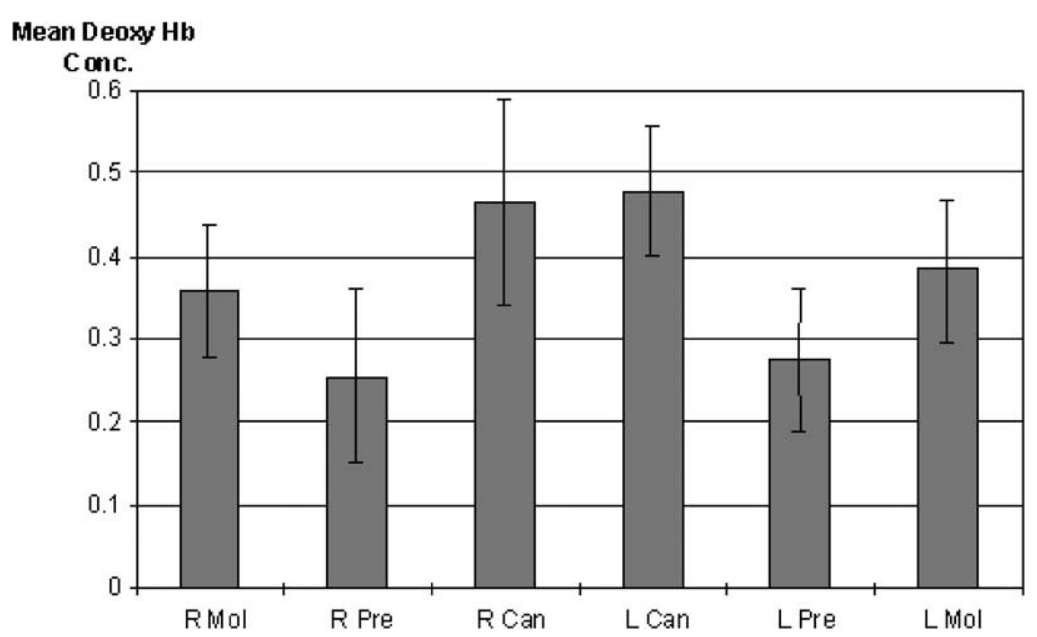

Fig. 4. Mean deoxyhaemoglobin concentrations averaging the measurements taken in the six days in the same subject. Error bars show the Confidence Interval (95\%). There was no statistical difference in the values observed when comparing the right side to the left, when averaging all the measurements (see Table 2).

Table 3

Mean deoxyhaemoglobin concentrations after 5 measurements in the volunteer group aged 20-30

\begin{tabular}{|c|c|c|c|c|c|c|}
\hline & R Mol & R Pre & R Can & L Can & L Pre & $\overline{\mathrm{L} \mathrm{Mol}}$ \\
\hline$\overline{\mathrm{CO}-24 \mathrm{~m}^{*}}$ & 0.597 & 0.359 & 0.612 & 0.509 & 0.407 & 0.343 \\
\hline MS-25m & 0.594 & 0.317 & 0.291 & 0.444 & 0.459 & 0.763 \\
\hline $\mathrm{AB}-26 \mathrm{~m}$ & 0.395 & 0.341 & 0.318 & 0.377 & 0.300 & 0.287 \\
\hline RR-27f & 0.624 & 0.550 & 0.397 & 0.470 & 0.424 & 0.519 \\
\hline NG-27f & 0.294 & 0.227 & 0.506 & 0.329 & 0.244 & 0.218 \\
\hline AN-29m & 0.453 & 0.453 & 0.476 & 0.623 & 0.379 & 0.239 \\
\hline MR-29f & 0.384 & 0.255 & 0.317 & 0.314 & 0.255 & 0.222 \\
\hline PG-29m & 0.465 & 0.368 & 0.556 & 0.438 & 0.401 & 0.349 \\
\hline $\mathrm{NC}-30 \mathrm{~m}$ & 0.559 & 0.475 & 0.537 & 0.501 & 0.448 & 0.394 \\
\hline PR-30m & 0.475 & 0.430 & 0.620 & 0.462 & 0.342 & 0.537 \\
\hline Mean & 0.484 & 0.377 & 0.463 & 0.447 & 0.366 & 0.387 \\
\hline Standard deviation & 0.108 & 0.101 & 0.124 & 0.091 & 0.077 & 0.174 \\
\hline Confidential interval & 0.067 & 0.062 & 0.077 & 0.057 & 0.048 & 0.108 \\
\hline Standard error & 0.049 & 0.052 & 0.058 & 0.043 & 0.040 & 0.089 \\
\hline
\end{tabular}

Note: ${ }^{*}$ Volunteer initials, age and gender (m or $\mathrm{f}$ ).

\subsection{Age correlations}

The following three figures show the correlation and regression graphs and coefficients for the deoxyhaemoglobin concentration with age in the six mandibular sites. This correlation was done using the averaged measurements of the 30 volunteers.

As can be noted in the graphs, the correlation was negative in the canine area (Fig. 5), and positive in the premolar and molar areas (Figs 6 and 7). This was consistent in both sides of the mandible. However, the data was very scattered, and the correlation coefficients and R-squares were very low, suggesting very weak or no correlation at all. 
Table 4

Mean deoxyhaemoglobin concentrations after 5 measurements in the volunteer group aged 31-50

\begin{tabular}{|c|c|c|c|c|c|c|}
\hline & R Mol & R Pre & R Can & L Can & L Pre & $\mathrm{L} \mathrm{Mol}$ \\
\hline ND-31m* & 0.268 & 0.315 & 0.517 & 0.509 & 0.400 & 0.400 \\
\hline $\mathrm{RS}-31 \mathrm{~m}$ & 0.261 & 0.265 & 0.165 & 0.317 & 0.160 & 0.194 \\
\hline FK-32m & 0.561 & 0.413 & 0.682 & 0.624 & 0.506 & 0.663 \\
\hline$B M-32 f$ & 0.504 & 0.354 & 0.623 & 0.409 & 0.311 & 0.430 \\
\hline MG-34m & 0.376 & 0.299 & 0.566 & 0.570 & 0.515 & 0.355 \\
\hline VM-35f & 0.275 & 0.310 & 0.169 & 0.326 & 0.293 & 0.333 \\
\hline SR-36m & 0.676 & 0.476 & 0.841 & 1.100 & 0.531 & 0.544 \\
\hline DK-37m & 0.392 & 0.448 & 0.494 & 0.723 & 0.402 & 0.475 \\
\hline$J W-45 f$ & 0.314 & 0.329 & 0.483 & 0.356 & 0.289 & 0.235 \\
\hline MC-47f & 0.681 & 0.958 & 0.491 & 0.420 & 0.356 & 0.644 \\
\hline Mean & 0.431 & 0.417 & 0.503 & 0.535 & 0.376 & 0.427 \\
\hline Standard deviation & 0.164 & 0.202 & 0.208 & 0.240 & 0.119 & 0.158 \\
\hline Confidential interval & 0.102 & 0.125 & 0.129 & 0.149 & 0.074 & 0.098 \\
\hline Standard error & 0.079 & 0.099 & 0.093 & 0.104 & 0.061 & 0.076 \\
\hline
\end{tabular}

Note: ${ }^{*}$ Volunteer initials, age and gender ( $\mathrm{m}$ or $\left.\mathrm{f}\right)$.

Table 5

Mean deoxyhaemoglobin concentrations after 5 measurements in the volunteer group aged 51-84

\begin{tabular}{|c|c|c|c|c|c|c|}
\hline & R Mol & R Pre & R Can & L Can & L Pre & $\mathrm{L} \mathrm{Mol}$ \\
\hline KG-54f* & 0.330 & 0.642 & 0.341 & 0.418 & 0.455 & 0.423 \\
\hline PL-55m & 0.362 & 0.392 & 0.537 & 0.545 & 0.361 & 0.252 \\
\hline BP-58f & 0.264 & 0.292 & 0.288 & 0.383 & 0.270 & 0.249 \\
\hline MF-60f & 0.423 & 0.385 & 0.241 & 0.161 & 0.125 & 0.275 \\
\hline JC-63m & 1.144 & 0.896 & 0.823 & 0.945 & 0.886 & 0.808 \\
\hline NL-67m & 0.791 & 0.709 & 0.633 & - & - & - \\
\hline AM-76m & 0.458 & 0.329 & 0.278 & 0.387 & 0.362 & 0.553 \\
\hline VP-77f & 0.374 & 0.228 & 0.193 & 0.260 & 0.290 & 0.280 \\
\hline MW-84f & - & 0.620 & 0.522 & 0.543 & 0.524 & - \\
\hline AP- $84 m$ & 0.475 & 0.439 & 0.431 & 0.544 & 0.500 & 0.386 \\
\hline Mean & 0.513 & 0.493 & 0.429 & 0.465 & 0.419 & 0.403 \\
\hline Standard deviation & 0.279 & 0.213 & 0.200 & 0.223 & 0.215 & 0.195 \\
\hline Confidential interval & 0.173 & 0.132 & 0.124 & 0.138 & 0.133 & 0.121 \\
\hline Standard error & 0.130 & 0.096 & 0.096 & 0.109 & 0.111 & 0.108 \\
\hline
\end{tabular}

Notes: ${ }^{*}$ Volunteer initials, age and gender ( $\mathrm{m}$ or f); - areas impossible to be scanned (bone grafts or difficult access).

The strongest correlation was observed in the right premolar area, with a correlation coefficient of 0.297995 and $R$-square of 0.08888 . The lowest correlation coefficient was -0.02546 with an $R$-square value of 0.0006 on the left canine area.

\subsection{Radiotherapy patients}

Despite having such poor results with volunteer measurements in terms of reproducibility we decided to scan patients that had radiotherapy, to see if any significant difference could be seen between these measurements compared to healthy volunteers. Table 6 shows a summary of the measurements per- 


\section{Mean Deoxy Hb Conc. Right Side}

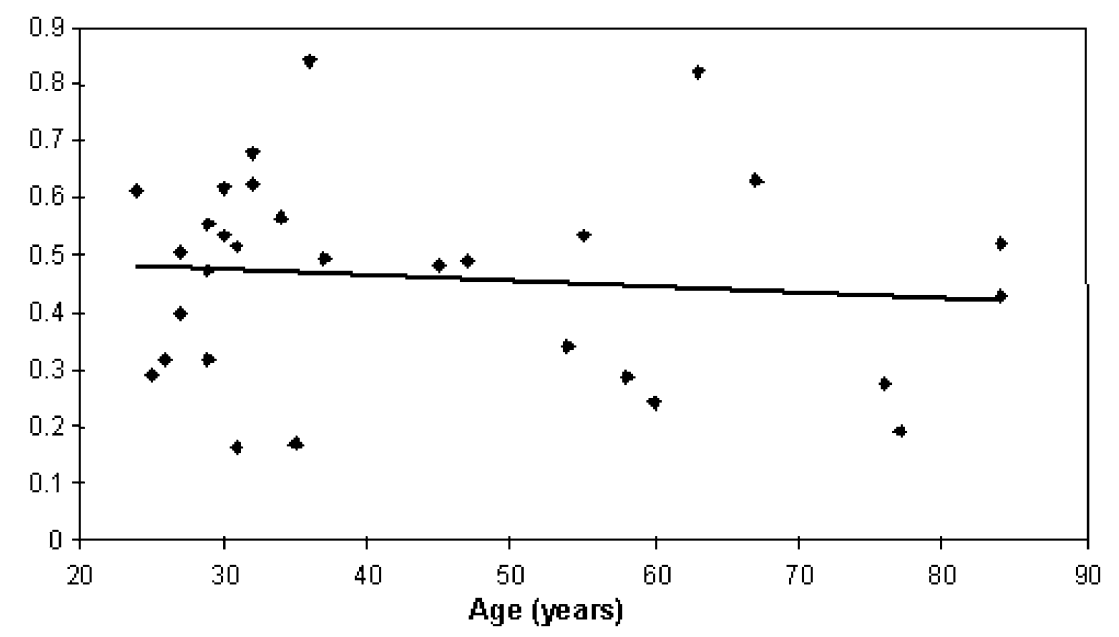

Mean Deoxy Hb Conc. $\quad$ Left Side

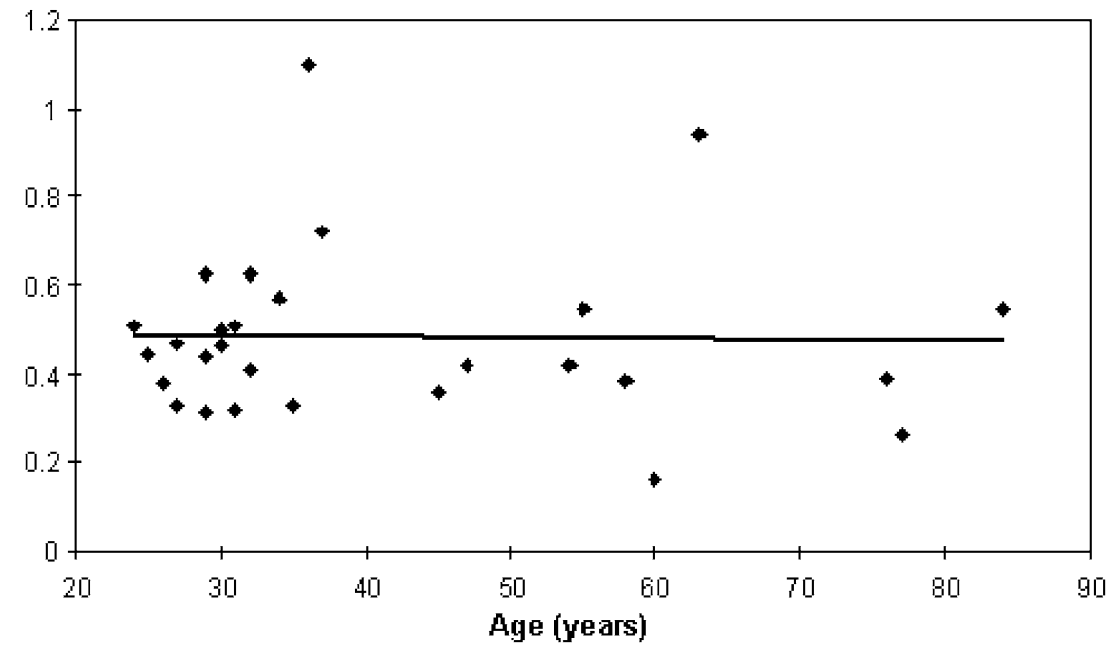

Fig. 5. Regression and correlation of deoxyhaemoglobin concentration with age in the canine area. Correlation coefficient: right side $=-0.11873\left(R^{2}=0.0141\right)$; left side $=-0.02546\left(R^{2}=0.0006\right)$.

formed. Again, each patient was scanned 5 times in order to try to reduce variability. Figure 8 shows the mean values and confidence intervals obtained for this group.

The sites that received the main radiotherapy treatment were reordered so that all are listed in the left side of the table, although some patients had treatment on the right side.

By comparing the main radiotherapy site to the other site of the mandible using $t$-test for unpaired samples, no significant differences were noted, and the following p values were obtained: molar area $(p=0.66548)$, premolar area $(p=0.38012)$, and canine area $(p=0.58788)$. Furthermore, when using single factor ANOVA comparing all the sites, the $p$-value remained not significant $(p=0.850309)$. Therefore, there could not be detected any difference between the radiotherapy site and the other site of the mandible. 


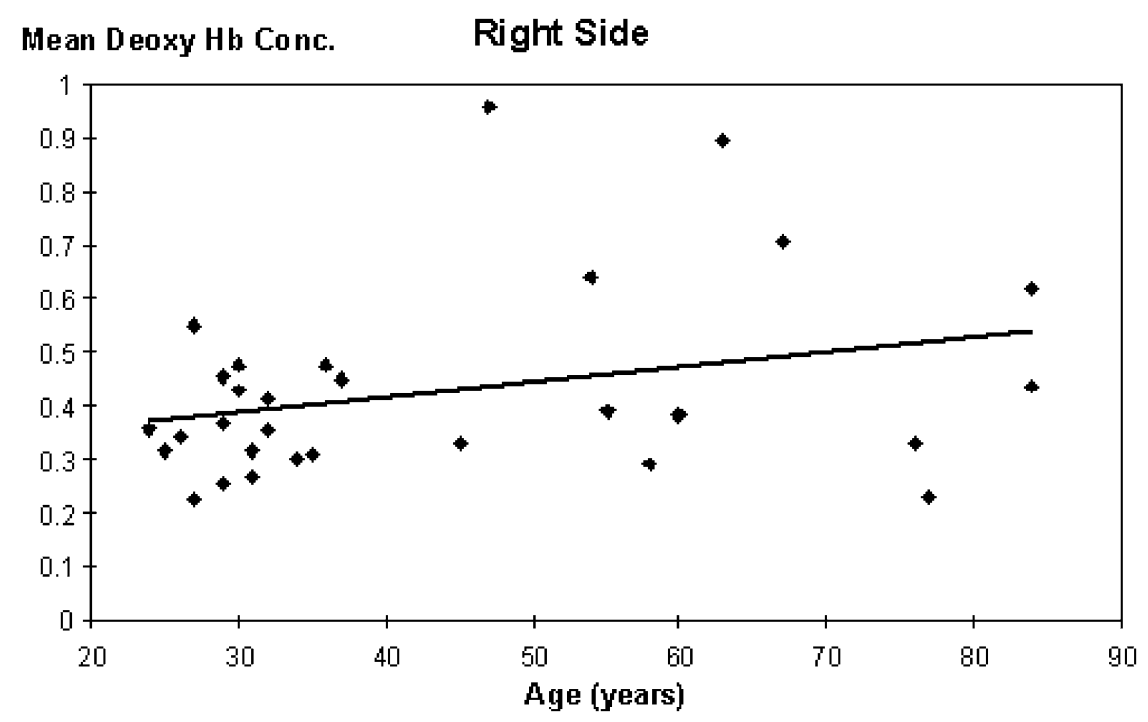

Mean Deoxy Hb Conc.

Left Side

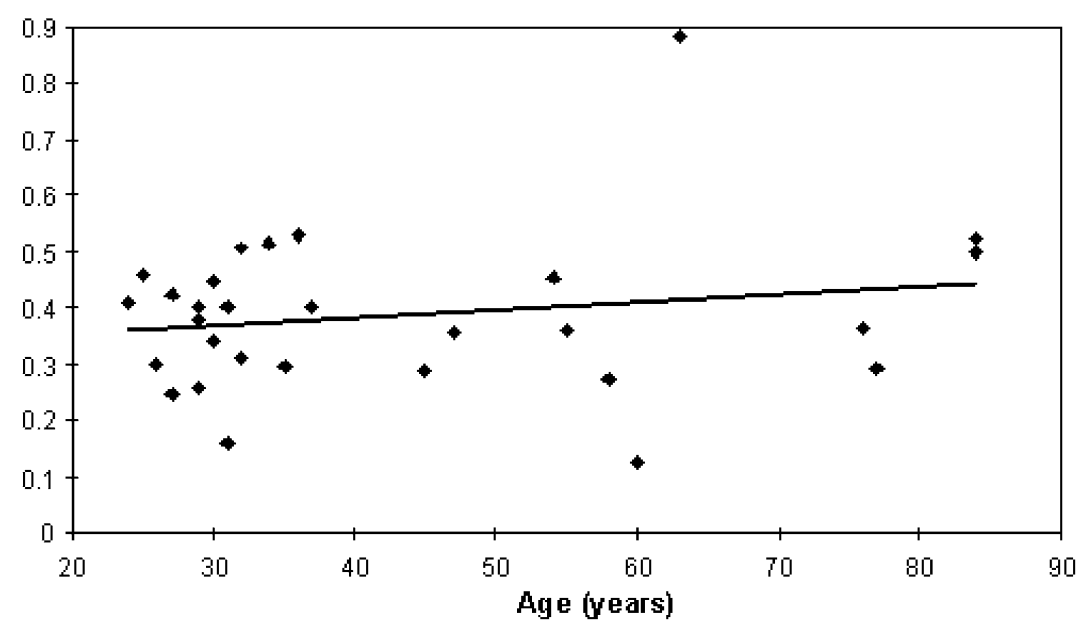

Fig. 6. Regression and correlation of deoxyhaemoglobin concentration with age in the premolar area. Correlation coefficient: right side $=0.297995\left(R^{2}=0.08888\right)$; left side $=0.181247\left(R^{2}=0.0329\right)$.

The radiotherapy group of patients was also compared to a group of 10 volunteers that where gender and age matched (Fig. 9). As can be seen graphically little difference can be observed when comparing these two groups. The $t$-test values obtained when comparing each side are shown in the graph (Fig. 9), and show hat there is no significant difference between the radiotherapy and the control group.

\section{Discussion}

Near infrared spectroscopy (NIRS) is a recognised non invasive method, used largely to monitor cerebral tissue oxygenation [11,31,32,45,58], ischemic changes in neonates [60], and describe the measur- 

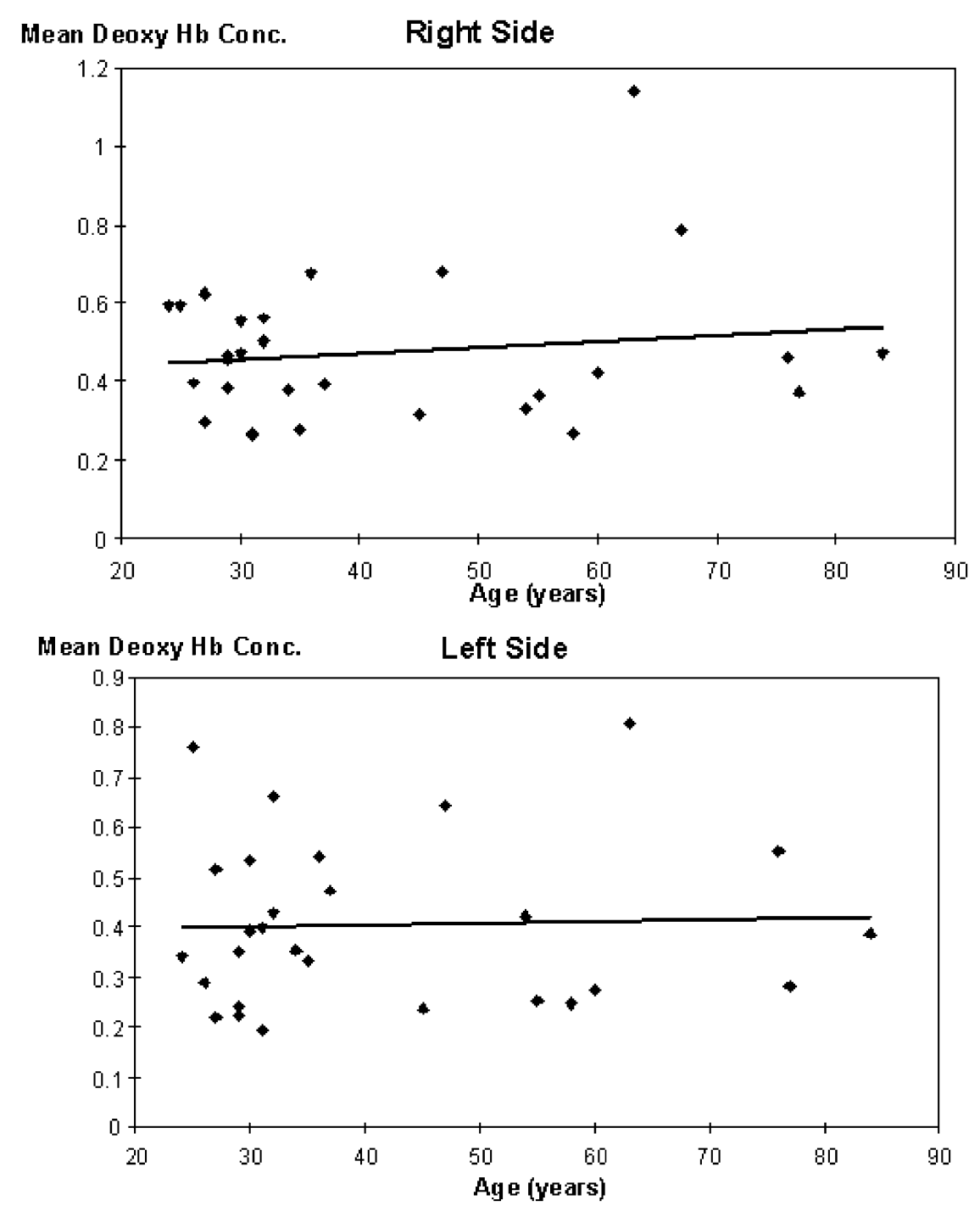

Fig. 7. Regression and correlation of deoxyhaemoglobin concentration with age in the molar area. Correlation coefficient: right side $=0.147192\left(R^{2}=0.0217\right)$; left side $=0.044377\left(R^{2}=0.002\right)$.

able response of normal tissue oxygenation after acute trauma [54]. Recently was also used to invasive catheter detection of lipid core coronary plaques [23,59], and even in helping caries detection [9].

Over the past three decades this technology has continued to grow, and today NIRS studies have found many niche applications in the fields of psychology, physiology, and cerebral pathology. The growing popularity of this technique is in part associated with a lower cost and increased portability of NIRS equipment when compared with other imaging modalities, such as functional magnetic resonance imaging and positron emission tomography. With this increasing number of applications, new techniques for the processing, analysis, and interpretation of NIRS data are continually being developed [32].

It has been used as an investigation method for osteoradionecrosis in retrospective studies, and showed a reduction of the amount of deoxygenated haemoglobin at sites of osteoradionecrosis, confirming that this is a hypovascular, hypoxic tissue with decreased metabolic rate subtracting little oxygen 
Table 6

Summary of the mean deoxyhaemoglobin concentrations in the radiotherapy patients group

\begin{tabular}{|c|c|c|c|c|c|c|}
\hline & R Mol & R Pre & R Can & L Can & L Pre & L Mol \\
\hline BC-36m* & 0.477 & 0.201 & 0.416 & 0.490 & 0.239 & 0.550 \\
\hline NM-41f & 0.461 & 0.441 & 0.269 & 0.426 & 0.477 & 0.469 \\
\hline$J R-45 f$ & 0.214 & 0.340 & 0.333 & 0.408 & 0.284 & 0.247 \\
\hline$J N-53 f$ & 0.169 & 0.195 & 0.135 & 0.187 & 0.169 & 0.156 \\
\hline$J R-55 f$ & 0.246 & 0.036 & 0.035 & 0.087 & 0.213 & 0.145 \\
\hline JR2-56f & 0.443 & 0.472 & 0.544 & 0.639 & 0.554 & 0.478 \\
\hline AR-57m & 0.305 & 0.228 & 0.455 & 0.564 & 0.324 & 0.287 \\
\hline IO-65m & 0.533 & 0.544 & 0.662 & 0.512 & 0.677 & 0.439 \\
\hline EH-65f & 0.446 & 0.369 & 0.517 & 0.554 & 0.748 & - \\
\hline PL-70m & 0.874 & 0.801 & 0.842 & 0.926 & 0.882 & 0.633 \\
\hline Mean & 0.417 & 0.363 & 0.421 & 0.479 & 0.457 & 0.378 \\
\hline Standard deviation & 0.204 & 0.217 & 0.241 & 0.232 & 0.250 & 0.175 \\
\hline Confidential interval & 0.126 & 0.134 & 0.149 & 0.144 & 0.155 & 0.108 \\
\hline Standard error & 0.100 & 0.114 & 0.117 & 0.106 & 0.117 & 0.095 \\
\hline
\end{tabular}

Note: ${ }^{*}$ Volunteer age and gender $(\mathrm{m}$ or $\mathrm{f})$.

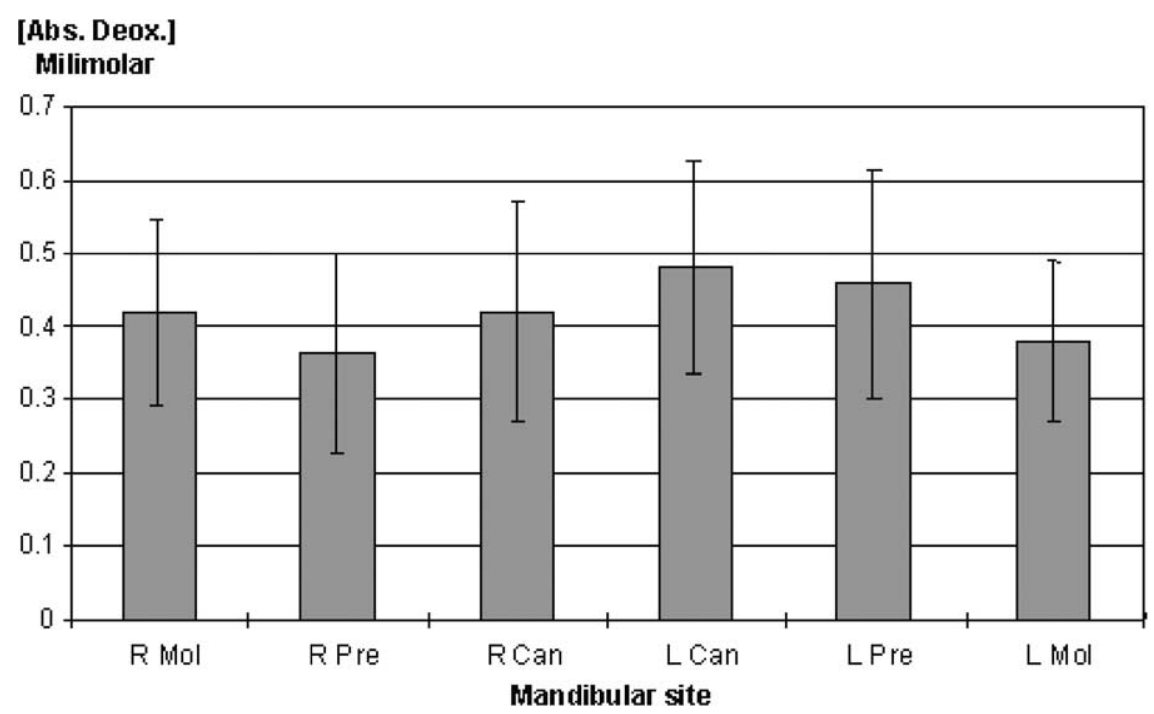

Fig. 8. Mean deoxyhaemoglobin concentrations averaging the measurements taken in the radiotherapy patients group. The sides were reordered so that the left side was the one that received the main radiotherapy treatment. Error bars show the confidence interval (95\%).

from haemoglobin [34,56]. Reductions in concentrations of deoxyhaemoglobin as reported in osteoradionecrosis may arise for three different reasons. (1) There may be a decreased volume of blood, and therefore both deoxygenated and oxygenated haemoglobin would be reduced. This is likely to occur after radiotherapy or in osteoradionecrosis because of the hypovascullarity seen histologically. (2) The proportion between oxy and deoxyhaemoglobin may be altered. This could happen due to a substantial increase in blood with oversupply of oxygen, and therefore proportionally less deoxyhaemoglobin. This is unlikely because of the endarteritis obliterans seen histologically. Finally, (3) there may be ad- 


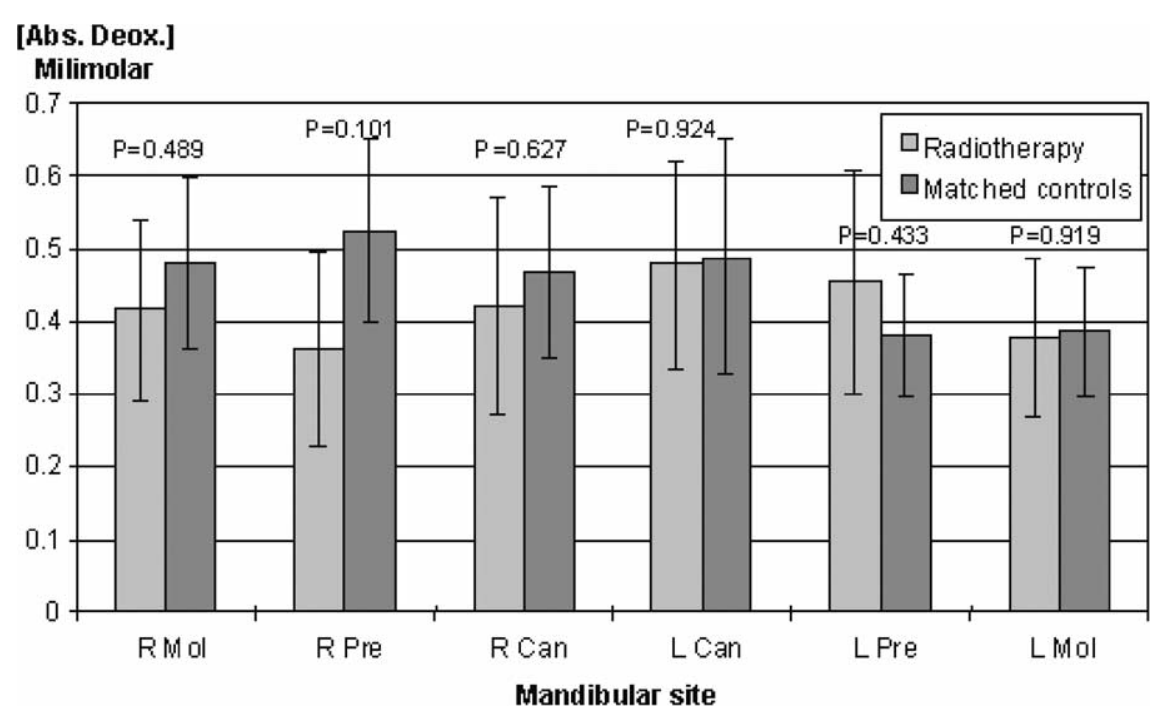

Fig. 9. Comparison between the radiotherapy and a group of gender and age matched controls $(n=10$ for each group). Bars show mean deoxyhaemoglobin concentrations, and error bars show the confidence interval (95\%). Above each pair of bars the $t$-test $p$-value is shown, comparing the two groups in that point.

equate blood flow and volume, but reduced metabolic demand in the irradiated tissue, extracting little oxygen from haemoglobin. The relative proportion of deoxygenated haemoglobin would therefore be reduced [34].

In the experiments reported here, only the concentrations of deoxyhaemoglobin have been measured, since the oxyhaemoglobin spectrum does not contain distinct features to permit absolute quantification. Techniques for absolute quantification of both tissue blood volume [60] and blood flow [15] have been developed but these currently require a manipulation of the patient's arterial oxygenation, which was not possible in the series, presented here. However, if we assume that the volume of tissue illuminated is similar in each patient and that the patients arterial haemoglobin saturation is $100 \%$, then it is possible to use the deoxyhaemoglobin concentration as an indirect indicator of tissue blood flow.

Keeping in mind the possibilities mentioned above, the present study was initially designed to evaluate prospectively a group of patients that would receive radiotherapy. These patients would have NIRS scans, and their levels of deoxyhaemoglobin would be monitored at regular intervals over a period of two years. A group of these patients would also receive a course of ultrasound therapy, in order to prevent or reverse any deleterious effects of radiotherapy.

Theoretically, the design of the study seemed correct, with age and gender matched controls as well. However, as soon as the first measurements started, a great variability of the results was noted, and the prospective trial was suspended until the NIRS measurements were properly validated. This validation was actually never performed in the previous publications related to the mandible.

The first step of the validation was to design a new probe that allowed simultaneous hold of the light source and the receiving optic fibre bundle. This was needed because in the previous investigation both probes were held by hand separately, and there was no consistent relationship between both, in terms of direction and positioning. It was also decided that all measurements should be performed as close as possible to the bone, our primary target. Therefore, the probes were designed taking this into account, with appropriate intra-oral angles. This avoided the light source being placed over the skin, thus avoiding the contributions of skin, subcutaneous tissue and muscles, as was done previously. Leung et 
al. [42] stated that the absolute values for blood flow and volume are often lower than those reported using other techniques such as positron emission tomography or magnetic resonance imaging (MRI), and the discrepancy is usually attributed to the effect of the overlying tissue layers, i.e., the skin, subcutaneous tissue and muscles on the optical pathlength used in the calculation and/or the assumption that the tissue is homogeneous. Optical measurements obtained on the surface of a head therefore measure absorptions due to the skin, subcutaneous tissue and muscles. It is well known that differences in subcutaneous fat thickness between subjects can influence the NIRS signal $[5,30,48]$. With this new probe, the light bundle always shined directly to the receiving bundle, and since both were connected in one instrument, the operator could now use the computer as well, so that only one person could do the measurements.

Thus, the following improvements were obtained with the new system: (1) the measurement is performed only through the mandible/mucosa, without the interference of the cheek; (2) the system is much more sensitive; (3) the system has a higher resolution, by a factor of 10 , and therefore the second differential has a far higher quality. This system should be able to measure bone deoxyhaemoglobin to a far higher precision than the old system [56].

To validate this new system, a series of scans were performed with one volunteer. Even so, great variability was noted, and it was decided to take not only one scan each time, but at least 5 . As mentioned, each of these scans consisted of 5 times $0.1 \mathrm{~s}$ exposition, which was summed. Then, 5 scans were taken and the calculations of absolute deoxyhaemoglobin concentrations were averaged. This reduced variability to some extent, but since we were planning a prospective trial, it would be important to see if these measurements, in a same patient, would remain relatively constant over time. Again, a volunteer was scanned on 6 different days over a three months period, as shown in Table 1 . The analysis of this data showed that the variability was still very high, and that the measurements taken each day were significantly different from the other days (Table 1). The only consistent reading was when comparing the right to the left side, where there were differences in some days, but generally there was no statistically significant difference between sides.

These preliminary studies really showed that caution should be used when planning the prospective trial. The deoxyhaemoglobin concentration changes expected after radiotherapy or ultrasound therapy would be probably very small, and these could possibly not be detected because of the great variability of the readings. Even so it was decided to continue the validation of the NIRS for the mandible, by evaluating the deoxyhaemoglobin levels change with age on a group of volunteers. A reduction of the levels of deoxyhaemoglobin over age would be expected. However, as shown in the results section, again a great variability of the measurements was noted, and no correlation at all could be identified between age and deoxyhaemoglobin concentration changes.

Finally, although the validation so far had produced disappointing results, it was decided to compare the measurements of a group of patients that received radiotherapy to the mandible, to a group of age and gender matched controls. The previous studies [34,56] showed a clear reduction of the deoxyhaemoglobin levels in the radiotherapy and osteoradionecrosis group. Unfortunately this could not be observed here (Fig. 9), as there was no statistical difference between both groups. This can be explained again by the great variability of the measurements and by the low number of patients examined $(n=10)$.

Although NIRS has been used successfully in several other areas as mentioned in the Introduction, it seems that for the mandible there is still more research needed. But our study was not the only one to find poor results with NIRS. Dullenkopf et al. [14] evaluated the NIRS based tissue haemoglobin index for continuous non-invasive monitoring of haemoglobin concentration during paediatric surgery, and 
they stated that their results support the need for caution, and that NIRS is a promising research tool, but not yet ready for routine clinical application for everything, as also stated Nicklin et al. [52]. Kim and Liu [39] showed that there could be a significant error in the determination of haemoglobin derivative concentrations using NIRS when the values of haemoglobin extinction coefficients have variations or uncertainties.

The variability of the measurements observed here was so high, that the only way we could show the changes we are interested in (radiotherapy and ultrasound effects), would be to evaluate a very large number of patients and volunteers. However, this would not be an easy task, since there are not many head and neck radiotherapy patients available, and even fewer patients with mandibular osteoradionecrosis, which occurs in approximately $2 \%$ of the radiotherapy patients.

The reason why the system did not work properly in terms of reproducibility of readings is probably because the mandible is relatively thin and the attenuation was low. Therefore if the attenuation features are small compared to the system noise, one can expect large variability in the results. In thicker bones, it may be possible to have more accurate readings.

\section{Conclusions}

In conclusion, the NIRS validation for the measurement of deoxyhaemoglobin concentrations in the mandible showed that the variability of the measurements was very high. This was shown by performing measurements in the same patient over a period of time, and by evaluating a group of 30 volunteers. An expected decrease in deoxyhaemoglobin concentration correlated to age in these volunteers could also not be observed. The measurements of patients that received radiotherapy to the mandible showed no significant differences to an age and gender matched control group. Therefore it can be concluded that NIRS in the conditions evaluated here, is not an appropriate diagnostic tool for the evaluation of radiotherapy effects on the mandibular blood flow and metabolic status. Further research is needed for more appropriate diagnostic tools to evaluate mandibular blood flow, oxygen consumption and metabolic status.

\section{References}

[1] K. Aitasalo and P. Ruotsalainen, Effects of irradiation on mandibular scintigraphy, The Journal of Nuclear Medicine 26 (1985), 1263-1269.

[2] J.M. Alexander, Radionuclide bone scanning in the diagnosis of lesions of the maxillofacial region, Journal of Oral Surgery 34 (1976), 249-256.

[3] M.R. Beehner and R.E. Marx, Hyperbaric oxygen induced tissue angiogenesis: a human histology and tissue oxygen tension study, in: Proceedings of the 65th Meeting of the American Association of Oral and Maxillofacial Surgeons, Abstracts from the Scientific Sessions, AAOMS, Rosemont, 1983, pp. 78-79.

[4] J.E. Brazy, D.V. Lewis, M.H. Mitnick and F.F. Jöbsis van der Vliet, Noninvasive monitoring of cerebral oxygenation in preterm infants: preliminary observations, Pediatrics 75 (1985), 217-225.

[5] M.J. Buono, P.W. Miller, C. Hom, R.S. Pozos and F.W. Kolkhorst, Skin blood flow affects in vivo near-infrared spectroscopy measurements in human skeletal muscle, The Japanese Journal of Physiology 55 (2005), 241-244.

[6] S. Cade, Malignant Disease and its Treatment by Radium, 2nd edn, Vol. 1, Simukin Marshall, London, 1941.

[7] C.B. Cairns, D. Fillipo and H.J. Proctor, A noninvasive method for measuring the effects of increased intracranial pressure with near infrared spectroscopy, Surgery Gynecology and Obstetrics 161 (1985), 145-148.

[8] T.R. Cheatle, L.A. Potter, M. Cope, D.T. Delpy, P.D.C. Smith and J.H. Scurr, Near-infrared spectroscopy in peripheral vascular disease, British Journal of Surgery 78 (1991) 405-408.

[9] L.P. Choo-Smith, C.C. Dong, B. Cleghorn and M. Hewko, Shedding new light on early caries detection, Journal of the Canadian Dental Association 74 (2008), 913-918. 
[10] B. Cohen and W.H. Stephenson, Post-irradiation fractures of the neck of the femur, The Journal of Bone and Joint Surgery, British Volume 38-B (1956), 830-845.

[11] C.E. Cooper, D.T. Delpy and E.M. Nemoto, The relationship of oxygen delivery to absolute haemoglobin oxygenation and mitochondrial cytochrome oxidase redox state in the adult brain: a near-infrared spectroscopy study, The Biochemical Journal 332 (1998), 627-632.

[12] M. Cope, The development of a near infrared spectroscopy system and its application for non invasive monitoring of cerebral blood and tissue oxygenation in the newborn infant, $\mathrm{PhD}$ thesis, University of London, 1991.

[13] M. Cope and D.T. Delpy, A system for long term measurement of cerebral blood and tissue oxygenation in newborn infants by near infrared transillumination, Medical and Biological Engineering and Computing 26 (1988), 289-294.

[14] A. Dullenkopf, U. Lohmeyer, B. Salgo, A.C. Gerber and M. Weiss, Non-invasive monitoring of haemoglobin concentration in paediatric surgical patients using near-infrared spectroscopy, Anaesthesia 59 (2004), 453-458.

[15] A.D. Edwards, J.S. Wyatt, C.E. Richardson, D.T. Delpy, M. Cope and E.O.R. Reynolds, Cotside measurements of cerebral blood flow in ill new-born infants by near infrared spectroscopy, The Lancet 2 (1988), 770-771.

[16] C.E. Elwell, A Practical User's Guide to Near Infrared Spectroscopy, UCL Reprographics, Hamamatsu, London, 1995.

[17] J.B. Epstein, G. Rea, F.L.W. Wong, J. Spinelli and P. Stevenson-Moore, Osteonecrosis: study of the relationship of dental extractions in patients receiving radiotherapy, Head and Neck Surgery 10 (1987), 48-54.

[18] J.B. Epstein, F.L.W. Wong, A. Dickens, I. Szasz and M. Lepawsky, Bone and gallium scans in postradiotherapy osteonecrosis of the jaw, Head and Neck 14 (1992), 288-292.

[19] M. Ethunandan, A. Birch, B.T. Evans and J.R. Goddard, Doppler sonography for the assessment of central mandibular blood flow, British Journal of Oral and Maxillofacial Surgery 38 (2000), 294-298.

[20] J. Ewing, Tissue reactions to radiation, American Journal of Roentgenology 15 (1926), 93-114.

[21] M. Ferrari, C. De Marchis, A. Di-Nichola, R. Agostino, S. Nodaris and G. Bucci, Cerebral blood volume and haemoglobin oxygen saturation monitoring in neonatal brain by near infrared spectroscopy, Advances in Experimental Medicine and Biology 200 (1986), 203-211.

[22] M. Fujita, K. Harada, N. Masaki, K. Shimizutani, S.W. Kim, N. Fujita, K. Sakurai, H. Fuchihata, T. Inone and T. Kozuka, MR imaging of osteoradionecrosis of the mandible following radiotherapy for head and neck cancer SM, Nippon Acta Radiological 51 (1991), 892-900.

[23] C.M. Gardner, H. Tan, E.L. Hull, J.B. Lisauskas, S.T. Sum, T.M. Meese, C. Jiang, S.P. Madden, J.D. Caplan, A.P. Burke, R. Virmani, J. Goldstein and J.E. Muller, Detection of lipid core coronary plaques in autopsy specimens with a novel catheter-based near-infrared spectroscopy system, Journal of the American College of Cardiology: Cardiovascular Imaging 1 (2008), 638-648.

[24] D.H. Glaister, Current and emerging technology in G-LOC detection: noninvasive monitoring of cerebral microcirculation using near infrared, Aviation, Space, and Environmental Medicine 59 (1988), 23-28.

[25] N.B. Hampson and C.A. Piantadosi, Near infrared monitoring of human skeletal muscle oxygenation during forearm ischaemia, Journal of Applied Physiology 64 (1988), 2449-2457.

[26] R. Hermans, E. Fossion, C. Ioannides, W. Van den Bogaert, J. Ghekiere and A.L. Baert, CT findings in osteoradionecrosis of the mandible, Skeletal Radiology 25 (1996), 31-36.

[27] W. Herschel, Experiments on the refrangibility of the invisible rays of the Sun, Philosophical Transaction of the Royal Society (London) 90 (1800), 284-292.

[28] W. Herschel, Experiments on the solar, and on the terrestrial rays that occasion heat; with a comparative view of the laws to which light and heat, or rather the rays which occasion them, are subject, in order to determine whether they are the same, or different. Part I, Philosophical Transaction of the Royal Society (London) 90 (1800), 293-326.

[29] W. Herschel, Experiments on the solar, and on the terrestrial rays that occasion heat; with a comparative view of the laws to which light and heat, or rather the rays which occasion them, are subject, in order to determine whether they are the same, or different. Part II, Philosophical Transaction of the Royal Society (London) 90 (1800), 437-538.

[30] S. Homma, T. Fukunaga and A. Kagaya, Influence of adipose thickness on near infrared spectroscopic signals in the measurement of human muscle, Journal of Biomedical Optics 1 (1996), 418-424.

[31] R. Hull, H. Bortfeld and S. Koons, Near-infrared spectroscopy and cortical responses to speech production, The Open Neuroimaging Journal 3 (2009), 26-30.

[32] T.J. Huppert, S.G. Diamond, M.A. Franceschini and D.A. Boas, HomER: a review of time-series analysis methods for near-infrared spectroscopy of the brain, Applied Optics 48 (2009), D280-D298.

[33] I.L. Hutchinson, Complications of radiotherapy in the head and neck: an orofacial surgeon's view, in: Current Radiation Oncology, J.S. Tobias and P.R.M. Thomas, eds, Arnold, London, 1996, pp. 144-177.

[34] I.L. Hutchinson, M. Colpe, D.T. Delpy, C.E. Richardson and M. Harris, The investigation of osteoradionecrosis of the mandible by near infrared spectroscopy, British Journal of Oral and Maxillofacial Surgery 28 (1990), 150-154.

[35] I.L. Hutchinson, I.D. Cullum, J.A. Langford, P.H. Jarritt, P.J. Ell and M. Harris, The investigation of osteoradionecrosis of the mandible by $99 \mathrm{mTc}-$ methylene diphosphonate radionuclide bone scans, British Journal of Oral and Maxillofacial Surgery 28 (1990), 143-149. 
[36] F.F. Jobsis, Noninvasive, infrared monitoring of cerebral and myocardial oxygen sufficiency and circulatory parameters, Science 198 (1977), 1264-1267.

[37] W. Kaye, Near-infrared spectroscopy, Spectrochimica Acta 6 (1954), 257-287.

[38] W. Kaye, Near-Infrared Spectroscopy II. Instrumentation and Technique, Spectrochimica Acta 7 (1955), 181-204.

[39] J.G. Kim and H. Liu, Variation of haemoglobin extinction coefficients can cause errors in the determination of haemoglobin concentration measured by near-infrared spectroscopy, Physics in Medicine and Biology 52 (2007), 62956322.

[40] M.A. King, D.A. Weber, G.W. Casaretti, F.A. Burgener and O. Corrivean, A study of irradiated bone. Part II: Changes in Tc-99m pyrophosphate bone imaging, The Journal of Nuclear Medicine 21 (1980), 22-30.

[41] G. Kok, Spontaneous fractures of the femoral neck after the intensive irradiation of carcinoma of the uterus, Acta Radiological 40 (1953), 511-527.

[42] T.S. Leung, C.E. Elwell and D.T. Delpy, Estimation of cerebral oxy- and deoxy-haemoglobin concentration changes in a layered adult head model using near-infrared spectroscopy and multivariate statistical analysis, Physics in Medicine and Biology 50 (2005), 5783-5798.

[43] L.N. Livera, Y.A. Wickramasinghe, S.A. Spencer, P. Rolfe and M.S. Thomiley, Cyclical fluctuations in cerebral blood volume, Archives of Disease in Childhood 67 (1992), 62-63.

[44] R.E. Marx, Osteonecrosis of the jaws: a review and update, HBO Review 5 (1984), 78-127.

[45] S.J. Matcher and C.E. Cooper, Absolute quantification of deoxyhaemoglobin concentration in tissue using near infrared spectroscopy, Physics in Medicine and Biology 39 (1994), 1295-1312.

[46] P. Maurer and L. Meyer, Osteoradionecrosis of the mandible - resection aided by measurement of partial pressure of oxygen (pO2): a technical report, Journal of Oral and Maxillofacial Surgery 64 (2006), 560-562.

[47] P. Maurer, L. Meyer, A.W. Eckert, M. Berginski and J. Schubert, Measurement of oxygen partial pressure in the mandibular bone using a polarographic fine needle probe, International Journal of Oral and Maxillofacial Surgery 35 (2006), 231-236.

[48] K. McCully, L. Landsberg, M. Suarez, M. Hofmann and J. Posner, Identification of peripheral vascular disease in elderly subjects with optical spectroscopy, The Journals of Gerontology: Series A, Biological Sciences and Medical Sciences 52 (1997), B159-B165.

[49] A.D. McGregor and D.G. MacDonald, Post irradiation changes in the blood vessels of the adult human mandibles, British Journal of Oral and Maxillofacial Surgery 33 (1995), 15-18.

[50] L. Meyer, P. Maurer and J. Schubert, Measurement of oxygen tension in bone. A new method and preliminary results, Journal of Oral and Maxillofacial Surgery 61(Suppl. 1) (2003), 30a.

[51] H. Minn, K. Aitasalo and R.P. Happonen, Detection of cancer recurrence in irradiated mandible using positron emission tomography, European Archives of Oto-Rhin-Laryngology 250 (1993), 312-315.

[52] S.E. Nicklin, I.A. Hassan, Y.A. Wickramasinghe and S.A. Spencer, The light still shines, but not that brightly? The current status of perinatal near infrared spectroscopy, Archives of Disease in Childhood. Fetal and Neonatal Edition 88 (2003), F263-F268.

[53] T. Semerigidis, E. Vairaktaris, I. Iatrou and C. Martis, Blood supply to the oral and maxillofacial tissues following radiation therapy: a prospective ultrasonographic study, Journal of Craniomaxillofacial Surgery 24 (1996), 16-23.

[54] M.S. Shuler, W.M. Reisman, T.E. Whitesides Jr, T.L. Kinsey, E.M. Hammerberg, M.G. Davila and T.J. Moore, Nearinfrared spectroscopy in lower extremity trauma, The Journal of Bone and Joint Surgery. American Volume 91 (2009), $1360-1368$.

[55] M.B. Taylor and J.G. Whitman, The current status of pulse oxymetry. Clinical value of continuous non-invasive oxygen saturation monitoring, Anaesthesia 41 (1986), 943-949.

[56] H. Telfah, Changes in blood flow, tissue metabolism and fat content in the irradiated mandible detected by means of near infrared spectroscopy (NIRS), MSc dissertation, Eastman Dental Institute, University of London, 1995, pp. 1-135.

[57] J.J. Thorn, F. Kallehave, P. Westergaard, E.H. Hansen and F. Gottrup, The effect of hyperbaric oxygen on irradiated tissues: transmucosal oxygen tension measurements, Journal of Oral and Maxillofacial Surgery 55 (1997), 1103-1107.

[58] J.D. Tobias, G.A. Johnson, S. Rehman, R. Fisher and N. Caron, Cerebral oxygenation monitoring using near infrared spectroscopy during one-lung ventilation in adults, Journal of Minimal Access Surgery 4 (2008), 104-107.

[59] S. Waxman, S.R. Dixon, P. L'Allier, J.W. Moses, J.L. Petersen, D. Cutlip, J.C. Tardif, R.W. Nesto, J.E. Muller, M.J. Hendricks, S.T. Sum, C.M. Gardner, J.A. Goldstein, G.W. Stone and M.W. Krucoff, In vivo validation of a catheter-based near-infrared spectroscopy system for detection of lipid core coronary plaques: initial results of the SPECTACL study, Journal of the American College of Cardiology: Cardiovascular Imaging 2 (2009), 858-868.

[60] J.S. Wyatt, M. Cope, D.T. Delpy, S. Wray and E.O.R. Reynolds, Quantification of cerebral oxygenation and haemodynamics in sick newborn infants by near infrared spectrophotometry, The Lancet 2 (1986), 1063-1066.

[61] J.S. Wyatt, A.D. Edwards, D. Azzopardi and E.O.R. Reynolds, Magnetic resonance and near infrared spectroscopy for investigation of perinatal hypoxic-ischaemic brain injury, Archives of Disease in Childhood 64 (1989), 953-963. 


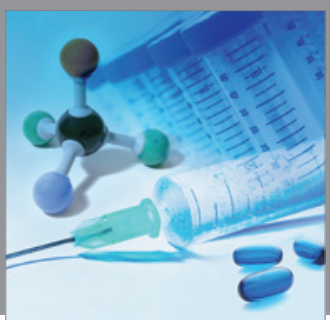

International Journal of

Medicinal Chemistry

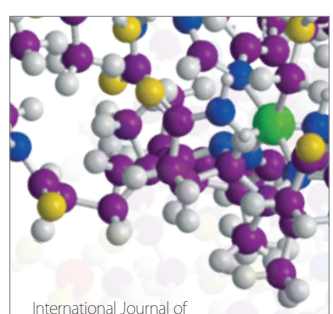

Carbohydrate Chemistry

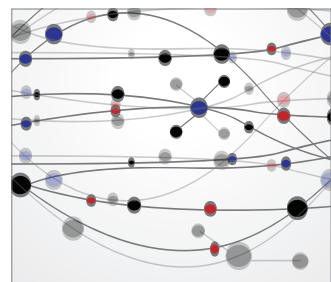

The Scientific World Journal
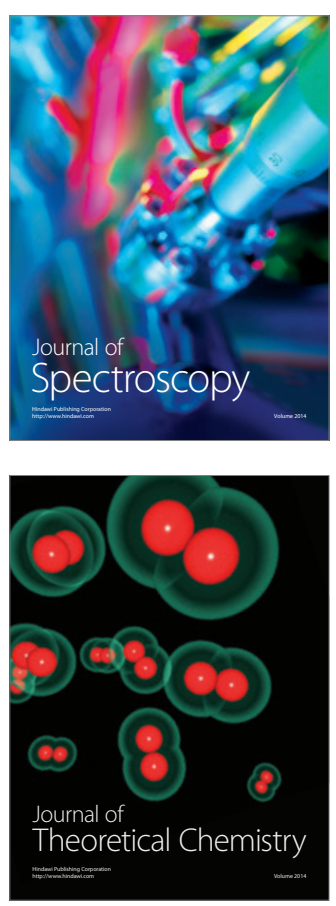
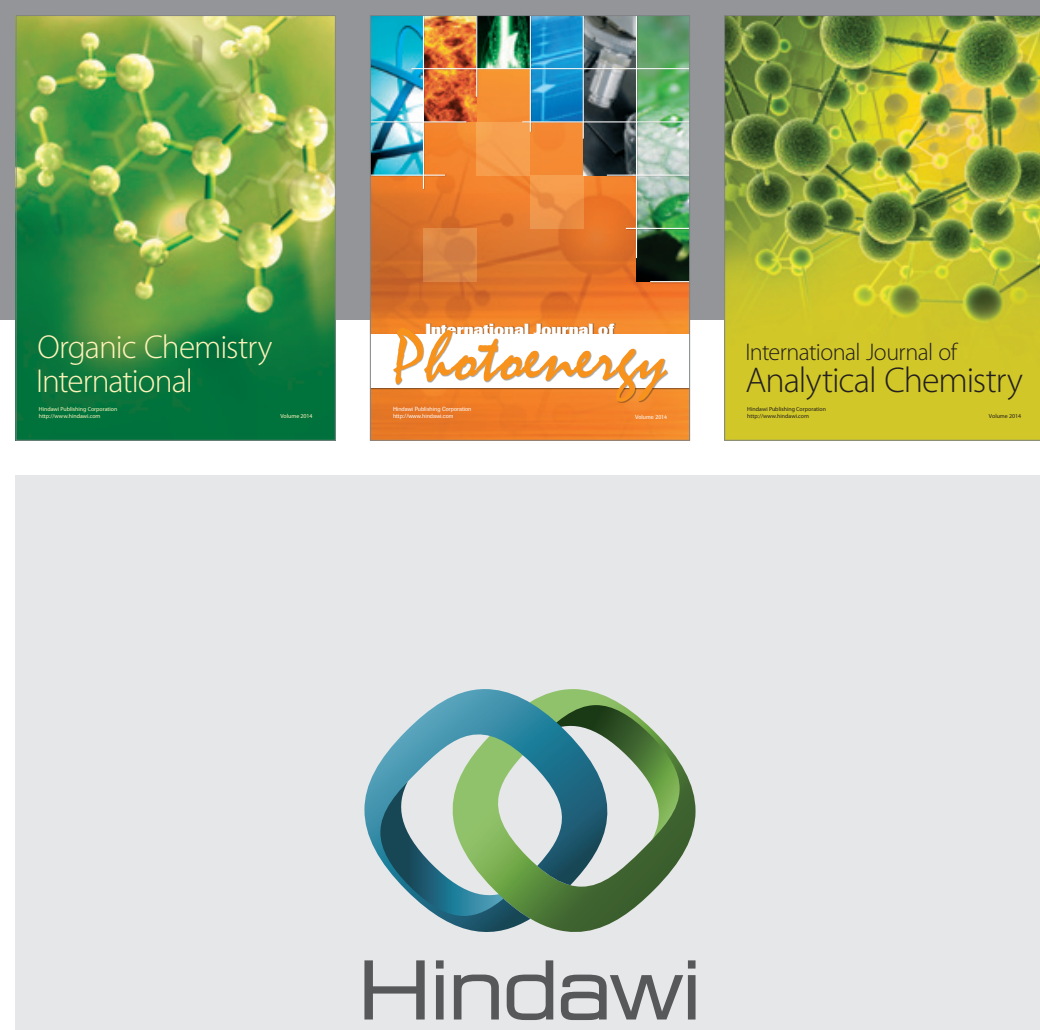

Submit your manuscripts at

http://www.hindawi.com
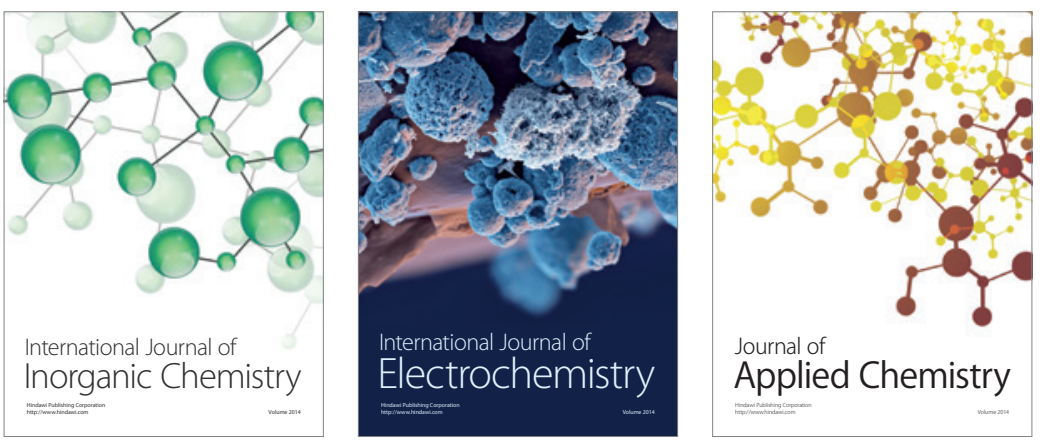

Journal of

Applied Chemistry
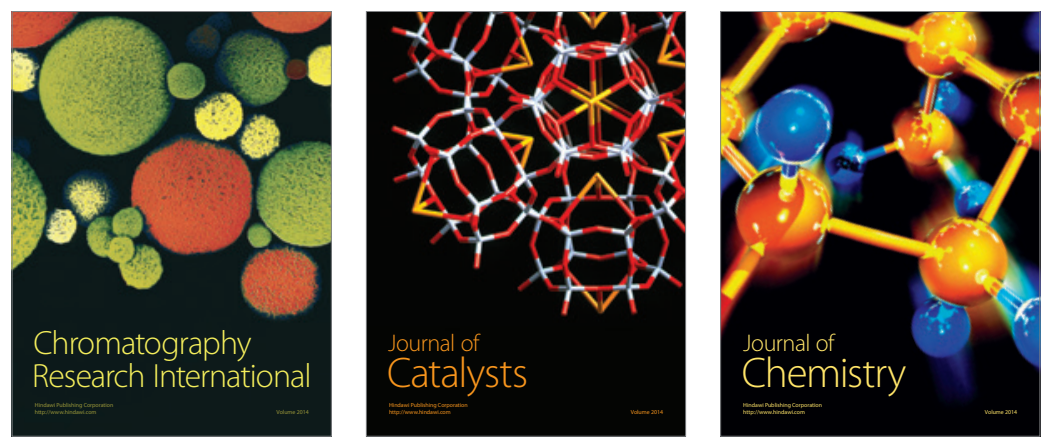
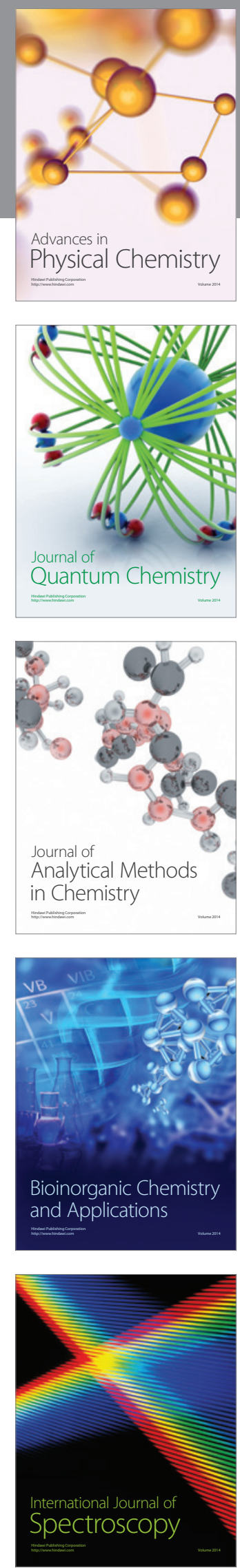